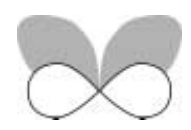

\title{
Variation in spectral reflectance among popula- tions of Dendrobates pumilio, the strawberry poison frog, in the Bocas del Toro Archipelago, Panama
}

Kyle Summers ${ }^{1,2 *}$, Thomas W. Cronin ${ }^{3}$ and Timothy Kennedy ${ }^{4}{ }^{1}$ Department of Biology and East Carolina University, Greenville, NC, USA, ${ }^{2}$ Smithsonian Tropical Research Institute, Apartado, Balboa, Republic of Panama, ${ }^{3}$ Department of Biology, University of Maryland at Baltimore County, Hilltop Circle, Baltimore, MD, USA and ${ }^{4}$ Department of Biology, McGill University, Montreal, Quebec, Canada

\begin{abstract}
Aim The goal of this study was to quantify levels of variation in spectral reflectance within and among populations of Dendrobates pumilio, the strawberry poison frog from the Bocas del Toro Archipelago.

Location This study was carried out in the Bocas del Toro Archipelago, in the Republic of Panama, Central America.

Methods Spectral reflectance was measured for samples of individuals from fifteen distinct island and mainland populations, using an Ocean Optics 2000 spectrometer and a BiLink portable computer.

Results Our results provide quantitative evidence for extreme polymorphism among populations, and more limited levels of polymorphism within some populations. No obvious signs of sexual dimorphism were found. All the colour morphs appear to have relatively little reflectance in the ultraviolet part of the spectrum. There is some evidence for clinal variation in colour and pattern across some mainland populations. There is also at least one area where distinctly different morphs occur in sympatry, suggesting the possibility of incipient reproductive isolation. We argue that variation in coloration may have been enhanced by sexual selection.
\end{abstract}

\section{Keywords}

Amphibian, neotropical, Central America, poison frog, spectral reflectance, colour, polymorphism, archipelago, aposematism, divergence.

\section{INTRODUCTION}

Animals have evolved colours for use as signals or physiological regulators in a variety of contexts, including aggressive and territorial displays, mating displays, aposematism, mimicry, crypsis and thermoregulation (Cott, 1940). Variation in colour is common both within and between populations in a vast array of animals, including mammals (e.g. Sutton \& Patterson, 2000), birds (e.g. Zink \& Remsen, 1986; Aldrich \& James, 1991), reptiles (e.g. McCoy et al., 1997), amphibians (e.g. Heyer, 1997), fish (e.g. Matthews,

*Correspondence: Department of Biology and East Carolina University, Greenville, NC 27858, USA. E-mail: summersk@mail.ecu.edu
1995), and insects (e.g. Anderson \& Peck, 1986). Colour or pattern polymorphism is widespread in anurans: it is found in at least thirty-five genera and eleven families (Hoffman \& Blouin, 2000). Numerous studies of anurans have documented geographical variation among populations (e.g. Duellman, 1973; Woodruff, 1975; Nussbaum \& Wu, 1995) and polymorphism within populations (reviewed in Hoffman \& Blouin, 2000).

One of the most dramatic examples of morphological variation within a single species of frog occurs in the Bocas del Toro Archipelago, in the Republic of Panama (Daly \& Myers, 1967; Myers \& Daly, 1983). Dendrobates pumilio O. Schmidt, the strawberry poison frog, displays dramatic variation in colour and pattern among island and mainland 
populations in this archipelago (Daly \& Myers, 1967; Myers \& Daly, 1983). The apparent colours of different populations span the entire range of the visual spectrum, ranging from blue to green to yellow to orange to red, with black and white as well and a number of distinctly different forms of patterning. Notwithstanding the dramatic differences in colour and pattern among populations, evidence from both acoustic analysis of call similarity (Myers \& Daly, 1976) and genetic analysis of DNA sequence similarity (Summers et al., 1997) indicate that the different populations are closely related and are members of the same species.

In spite of the interest generated by these polymorphic poison frog populations, there have been no published descriptions that quantify variation in colour either within or among the populations. In this paper, we present spectrometric analyses of samples of individuals from fifteen different populations. Most of these populations appear distinctly different in colour to the human visual system. We also present data on the geographical distribution of colour and pattern morphs in the archipelago. These data provide the first quantitative evaluation of the extraordinary diversity in colour found in these populations of frogs and provide a starting point for further investigations of the evolution of this diversity.

We begin with a brief review of the proximate basis of colour variation, the ontogenetic and environmental correlates of such variation, and research on the forces that can generate variation in coloration (particularly various forms of natural or sexual selection).

The proximate mechanisms underlying variation in colour are still the subject of active investigation in frogs and other animals. Perceived colour is typically produced by colour pigments, which reflect specific wavelengths of light (Hoffman \& Blouin, 2000). Colour can also be produced by scattering or thin-layer interference caused by specific structures (e.g. tiny dense particles or air spaces). Blue colours are also frequently produced structurally. Pigments in animal skin are generally found in specialized cells called chromatophores. These cells can contain a variety of colour pigment granules, including carotenoids (yellow red), melanins (black), flavines (yellow), purines (white or silvery), pterins, porphyrins and bile pigments. Other colours like blue and green may be produced by mixtures of different kinds of chromatophores.

In anurans, two cell types typically control colour and pattern, melanophores (containing melanin) and chromatophores (containing other colour pigments). Melanophores contain melanosomes, which are organelles containing melanin. There are two main categories of chromatophores in anuran skin: non-reflecting and reflecting chromatophores. Non-reflecting chromatophores are divided into xanthophores (containing yellow pigments) and erythrophores (containing red pigments). Reflecting chromatophores are called iridophores and contain the purines guanine, hypoxanthine and adenine (Bagnara, 1966). These cell types may be combined to produce the specific colours seen in anuran skin. For example, xanthophores and iridophores may be placed above melanophores to produce a green colour (Browder, 1968).

Most frogs can lighten or darken their skin tone to some extent, although actual colour change is uncommon (Hoffman \& Blouin, 2000). Phenotypic plasticity in the expression of coloration and pattern in anurans is made possible because melanophores, although they typically lie underneath the chromatophores, have extensive processes that extend over the chromatophores. Hence, the melanosomes can migrate into the processes and obscure the colour pigments in the chromatophores, changing the colour of the frog (Frost-Mason et al., 1994).

The proximate mechanisms that generate variation in colour both within and between populations of frogs are poorly understood, although hormonal influences are believed to be important (Bagnara \& Fernandez, 1993). Dispersal of melanin-containing granules is controlled by the pituitary gland, which produces melanophore stimulating hormone (MSH) in response to visual cues and other stimuli. The influence of hormones on ontogenetic colour change has been investigated in a variety of species in the genus Hyperolius (Richards, 1982; Hayes \& Menendez, 1999).

The potential causes of colour and pattern variation within and between populations are diverse, including random factors such as genetic drift, as well as natural selection in the context of environmental variation and predation, and sexual selection in the context of competition and mate choice.

Associations between environmental aspects of the habitat and variation in colour within and among populations have been found in a variety of species (e.g. Dearn, 1984; Brown \& Thorpe, 1991). Thorpe, Malhotra and colleagues have developed sophisticated statistical techniques for assessing the correlation between environmental variation and variation in morphological characteristics such as colour and pattern (e.g. Gubitz, et al., 2000; Malhotra \& Thorpe, 2000). These authors have found significant correlations between coloration and habitat type (mainly vegetation type and precipitation) in island lizards. In frogs, there are no studies demonstrating correlations between coloration and geographically varying environmental variables.

In many cases, bright coloration appears to be associated with the advertisement of toxicity (aposematism), and this certainly seems likely to be an important factor in the evolution of bright coloration in the poison frogs (Summers \& Clough, 2001). In general, aposematism might be expected to favour convergence, rather than divergence, because toxic organisms with similar coloration should more effectively train predators (Mallet \& Joron, 1999). However, variation among aposematically coloured populations is not uncommon (e.g. Joron \& Mallet, 1999). There is no single generally accepted explanation for such variation, although a variety of hypotheses have been proposed. These include weak selection accompanied by genetic drift, random extinction of mimetic taxa in different communities, adaptation to different microhabitats in which different colours 
are more effective at advertising toxicity, and antagonistic coevolution involving coevolutionary chase of toxic models by non-toxic Batesian mimics (Mallet \& Joron, 1999; Speed \& Turner, 1999).

Research on a variety of taxa implicates sexual selection as an important selective force driving divergence in coloration between populations (e.g. Seehausen et al., 1997; Wiens et al., 1999). In the context of sexual selection, indicator, sensory drive and Fisherian runaway models can all produce rapid divergence in coloration (and other traits) among populations (Hill, 1994; Iwasa \& Pomiankowski, 1995). Currently there is evidence favouring the indicator model in some taxa (e.g. Hill, 1994, 2000), but not in others (Grether, 2000). Evidence for the influence of sensory drive on divergence has also been found (Boughman, 2001).

Phenotypic plasticity has also been shown to be associated with environmental variation in some cases (e.g. Kemp \& Jones, 2000). In frogs, a common environmental factor affecting the phenotypic expression of colour is temperature: warm and dry conditions cause the melanosome granules to contract, producing a paler frog; cold and damp conditions cause the melanosomes to disperse, producing a darker frog. This phenotypic plasticity may have a thermoregulatory function in some species (Passmore \& Carruthers, 1979). Some frogs undergo seasonal changes in coloration, but the environmental causes of those changes are still under investigation (Hoffman \& Blouin, 2000). Age-related changes in colour over the course of the adult life-history stage have also been observed in some species of frogs (e.g. Mackey, 1958; Haugen, 1992). A variety of frogs show changes in colour between the juvenile and adult stage of life history (Hoffman \& Blouin, 2000).

\section{MATERIALS AND METHODS}

Measurements of spectral reflectance were made with a portable spectrometer (Ocean Optics 2000), attached to a portable computer (Bi-Link Computer, Inc., Whittier, CA). Measurements were taken of captive frogs in the laboratory, and of frogs captured in the field. Frogs in the laboratory were illuminated with a halogen lamp (250 watts). In the field, natural background irradiance was used to illuminate the frogs. The spectrometer was calibrated frequently throughout each series of measurements, using a white diffuse reflectance standard (Spectralon, Labsphere, Inc., North Sutton, NH). Measurements were taken with either a $50 \mu \mathrm{m} \times 2 \mathrm{~m}$ or $400 \mu \mathrm{m} \times 2 \mathrm{~m}$ optic fibre. Spectral reflectance can be related to common names for colours as follows: spectral reflectance that peaks between 600 and $700 \mathrm{~nm}$ will appear orange or red, between 500 and $600 \mathrm{~nm}$ will appear green to yellow, and peaks around $400 \mathrm{~nm}$ appear blue. Three measurements were taken from each frog's dorsum, and three from the venter. Table 1 shows the populations from which measurements were taken. In the field, frogs were captured by hand and kept in plastic bags until they were measured, then they were released near the point of capture.
The sex of the frogs used was determined by examining the chin region, which is darker in males, and by playing calls at individuals to stimulate males to call. Spectral reflectance was recorded from the chin region of known males for comparison with other parts of the ventral region.

We sought to obtain at least ten frogs from each population sampled, but this was not always possible because of time constraints on our ability to search for frogs, as frogs of some populations were difficult to find. Variation in population density, frog coloration and habitat type all contributed to our ability to find and measure frogs at a particular location.

Recordings of the downward irradiance were made (using the spectrometer) at locations frequented by frogs in four different habitats, in order to assess the light qualities typically experienced by frogs in the different populations. These were made using the same instrument with which the spectral reflectances were measured, but for these a UVtransmitting cosine collector was placed at the end of the fibre optic and positioned so that if faced upwards (thereby measuring downwelling irradiance). The instrument plus the fibre optic and the cosine collector were radiometrically calibrated using an irradiance standard lamp (Ocean Optics LS1-CAL).

\section{RESULTS}

Figure 1 shows photographs of typical individuals for twelve of fifteen populations that were measured in this study. Figure 2 shows the geographical location of the different Colour morphs in the Bocas del Toro Archipelago, and on the adjacent mainland.

The results of the reflectance spectrometric analyses are presented in Figs 3-17. Each figure includes a set of panels, one for each individual sampled in the population. Each panel shows three measurements of the spectral reflectance from the dorsum (dark line) and venter (light line). Hence each figure shows variation both within and among frogs of the same population.

\section{Bocas Island}

The Bocas Island frogs [Figs $1 \mathrm{i}$ and 2 (population 1)] appear bright yellow on the venter and forest green on the dorsum. They have large black spots all over the dorsum and on the forelimbs and hindlimbs. The spectral reflectances for the dorsal surface of these frogs generally show a peak around $550 \mathrm{~nm}$ in the visual spectrum, accounting for their green appearance (Fig. 3). The ventral surfaces generally peak around $550 \mathrm{~nm}$, but maintain high levels of reflectance between 550 and $600 \mathrm{~nm}$, accounting for their bright yellow appearance. The Bocas Island frogs live in both primary and secondary forest, and are even found living in large bromeliads in trees along the coast. This results in a variety of different light environments, but the typical environment probably corresponds to that of forest with a closed canopy but relatively open understory (similar to the irradiance show in Fig. 18a). 


\begin{tabular}{|c|c|c|c|}
\hline Location & Map no. & Sample size & Colour and pattern \\
\hline 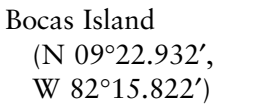 & 1 & 6 & Green with spots, Yellow venter \\
\hline $\begin{array}{l}\text { Solarte Island } \\
\qquad\left(\mathrm{N} 09^{\circ} 19.594^{\prime} \text {, }\right. \\
\left.\text { W } 82^{\circ} 12.568^{\prime}\right)\end{array}$ & 2 & 18 & Orange dorsum, White venter \\
\hline 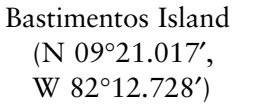 & 3 & 12 & $\begin{array}{l}\text { Red dorsum (variable) with spots, } \\
\text { White Venter }\end{array}$ \\
\hline Water Cay & 4 & 11 & Green dorsum, Yellow venter \\
\hline $\begin{array}{l}\text { Pope Island } \\
\text { (N 099.486', } \\
\left.\text { W } 82^{\circ} 8.572^{\prime}\right)\end{array}$ & 5 & 10 & Green dorsum, Yellow venter \\
\hline $\begin{array}{l}\text { Aguacate Peninsula } \\
\text { (N 099.090', } \\
\left.\text { W 82 } 10.791^{\prime}\right)\end{array}$ & 6 & 12 & Blue dorsum and venter \\
\hline $\begin{array}{l}\text { San Cristobal Island } \\
\left(\mathrm{N} 09^{\circ} 16.405^{\prime} \text {, }\right. \\
\left.\text { W } 82^{\circ} 16.292^{\prime}\right)\end{array}$ & 7 & 1 & Red dorsum with spots, Blue legs \\
\hline Pelican Cay & 8 & 11 & Green-yellow, Dorsum and venter \\
\hline $\begin{array}{l}\text { Sheperd Island } \\
\left(\text { N } 09^{\circ} 14.233^{\prime} \text {, }\right. \\
\left.\text { W } 82^{\circ} 19.768^{\prime}\right)\end{array}$ & 9 & 12 & Green-yellow, Dorsum and venter \\
\hline $\begin{array}{l}\text { Almirante } \\
\qquad\left(\mathrm{N} 09^{\circ} 13.976^{\prime},\right. \\
\left.\text { W } 82^{\circ} 22.925^{\prime}\right)\end{array}$ & 10 & 9 & Red dorsum, Blue legs \\
\hline $\begin{array}{l}\text { Uyama River } \\
\qquad\left(\mathrm{N} 09^{\circ} 10.332^{\prime} \text {, }\right. \\
\left.\text { W } 82^{\circ} 18.775^{\prime}\right)\end{array}$ & 11 & 11 & Black and white dorsum and venter \\
\hline Robalo & 12 & 1 & Yellow and black dorsum and venter \\
\hline 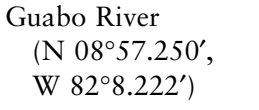 & 13 & 11 & Green dorsum and venter \\
\hline 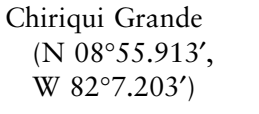 & 14 & 5 & Salmon dorsum, Green venter \\
\hline $\begin{array}{l}\text { Rambala } \\
\left(\mathrm{N} \mathrm{08} 54.368^{\prime},\right. \\
\left.\text { W } 82^{\circ} 11.135^{\prime}\right)\end{array}$ & 15 & 3 & Mixed population (see text) \\
\hline
\end{tabular}

Table I Location, number of individuals and colour and pattern of D. pumilio morphs sampled for this study. Numbers in parentheses correspond to numbers on the map representing the location of each population sampled (Fig. 2)

\section{Nancy Key}

On Nancy Key [Figs $1 \mathrm{k}$ and 2 (population 2)] the frogs appear bright orange, with an orange or white venter. The spectral reflectances of the dorsal surfaces of these frogs show a sharp inflection between 550 and $600 \mathrm{~nm}$, and a peak between 625 and $675 \mathrm{~nm}$, demonstrating their strong reflectance in the orange and red part of the visual spectrum (Fig. 4). There is typically some decline in reflectance between 650 and $700 \mathrm{~nm}$, which may be the reason that the frogs appear more orange than the Almirante frogs (see below). The frogs on Nancy Key are found in forest along the main spine of island. This forest has a high, relatively closed canopy, with a fairly open understory. The typical irradiance for this forest is shown in Fig. 18a.

\section{Bastimentos}

The Bastimentos Island frogs [Figs $1 \mathrm{j}$ and 2 (population 3)] typically appear to have a red or orange dorsum with large black spots and a white venter. However, this is one of the most variable populations in the archipelago, with a wide variety of colour morphs including yellow, green and white frogs (all with spots). This variation can be seen in 

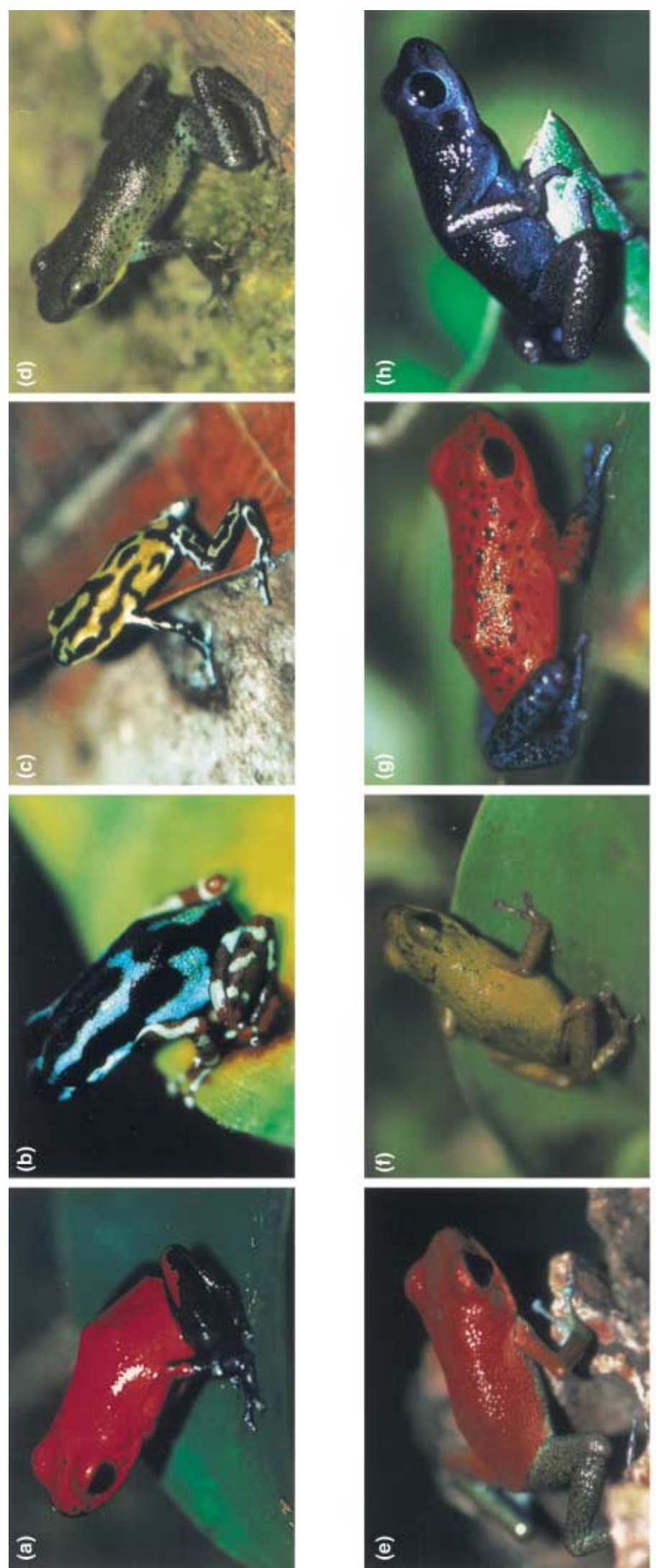
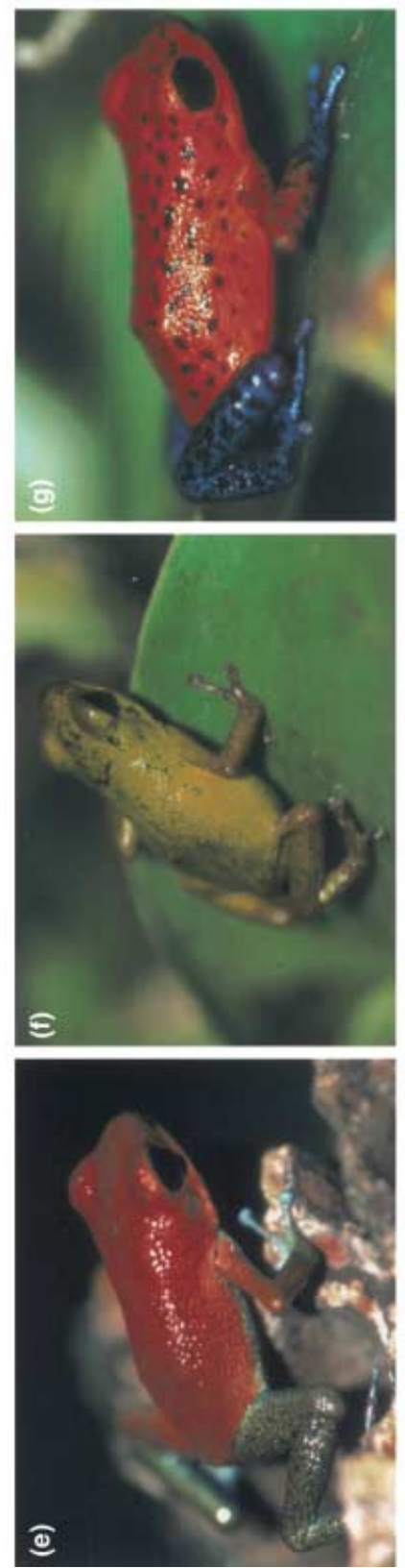

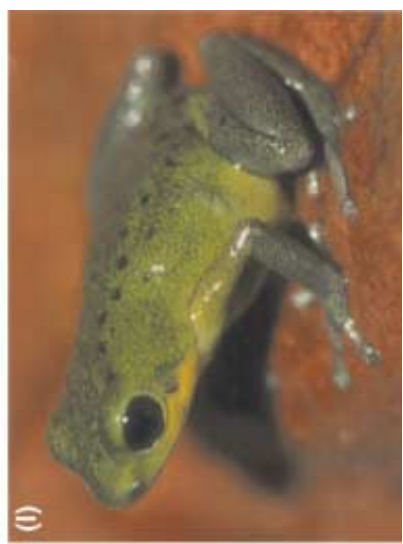

ปัँ

$\frac{5}{2}, 00$

है ची

은

离苛营

这

过

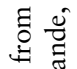

है

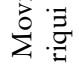

表

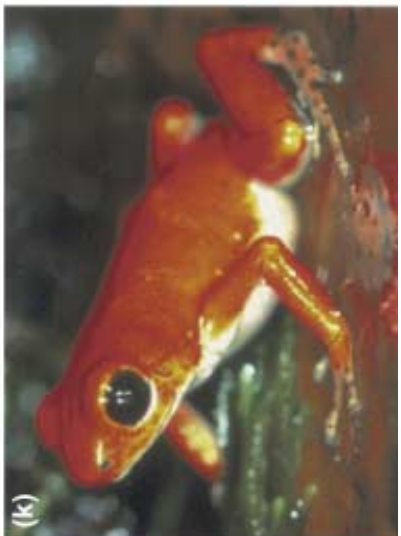

음

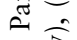

家高

물

氙 或

पे

究

s

要

웡

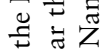

$\Xi \Xi \bar{\Xi}$

응

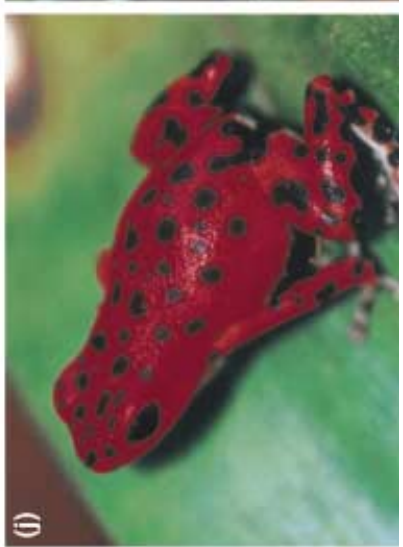

₹

$\Xi$.

s

ปี 은

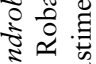

ธับ ๓

낭

品 ซే

윙흐음

a

苞䓀

舟

范

焉

흠돈

它芯至

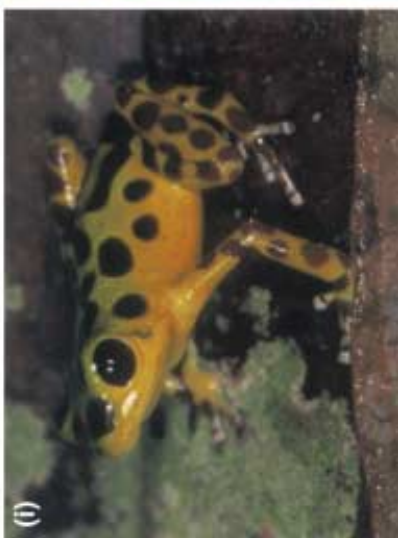

苞

品.

於

党光总

4

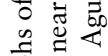

空

앙

웅

-

过

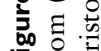

win 


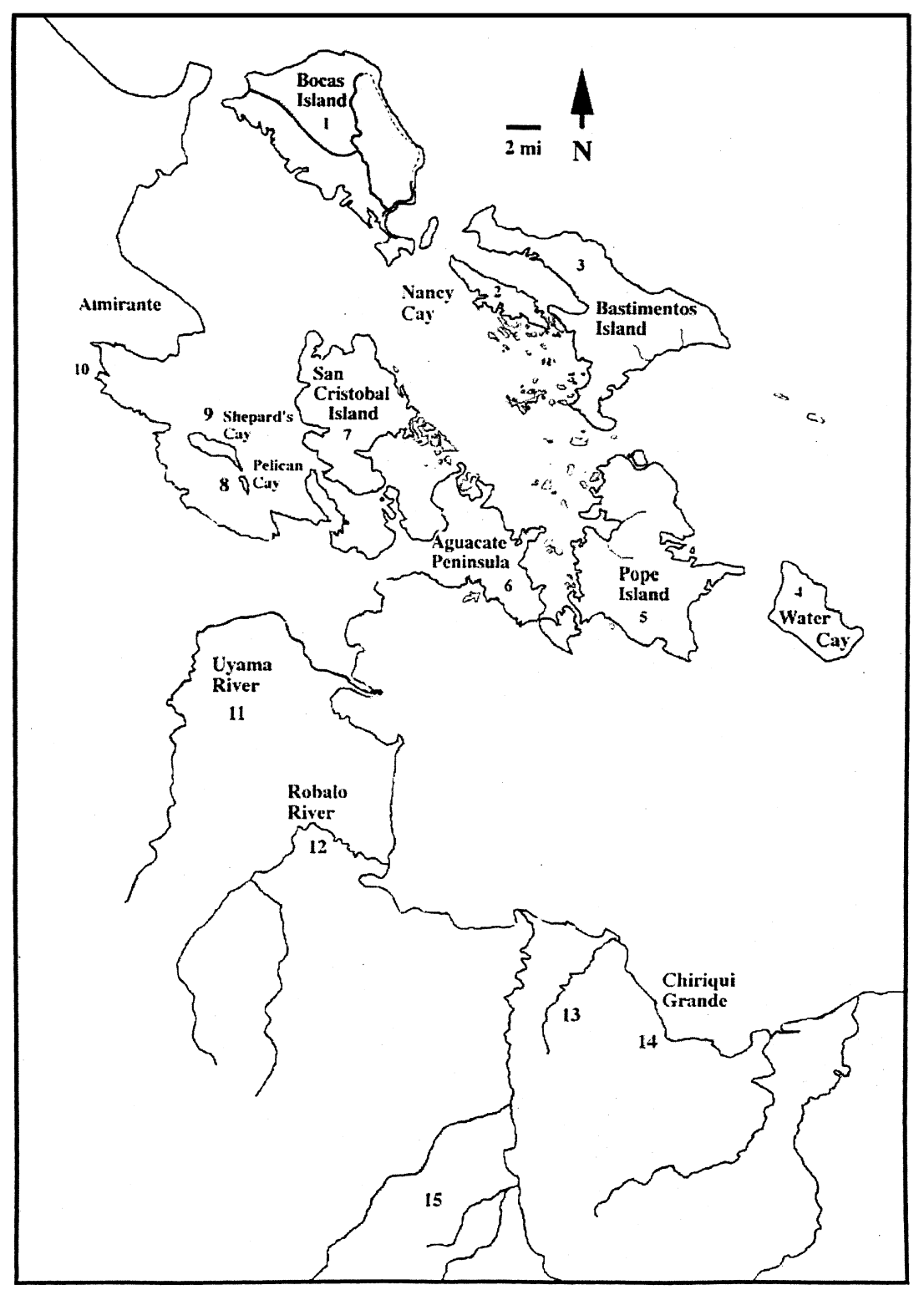

Figure 2 Map of the Bocas del Toro Archipelago, showing the location of populations sampled in this study. differences among the dorsal spectral reflectances of these frogs (Fig. 5). Some frogs show peak reflectance in the $600-650 \mathrm{~nm}$ region of the spectrum, whereas others show substantial reflectance in the yellow, green and even blue parts of the spectrum. Ventral surfaces of these frogs typically showed substantial reflectance across the visible spectrum, accounting for their usual white appearance. These frogs live in the forest from the coast right up onto the spine of the island. In general, the forest has a high canopy with a relatively open understory, and substantial clearing by humans has decreased the density of understory vegetation. Figure $18 \mathrm{~b}$ shows the irradiance measured in the typical habitat of the Bastimentos frogs we measured. The degree of variation in colour on this island appears to be clinal, with a higher degree of variation near the town of Bastimentos on the north-west tip of the island. Non-red morphs appear to be less common moving south-east of this population, but this has not been quantified and requires further investigation.

\section{Water Key}

The Water Key [Fig. 2 (population 4)] frogs appear to have forest green dorsal colour, with bright yellow venters. Figure 6 shows the spectral reflectance for this population. Both the dorsal and ventral spectral reflectances are similar to those measured on the Bocas Island frogs, with the dorsal surfaces showing a peak around $550 \mathrm{~nm}$, and the ventral surfaces showing a peak at around the same wavelength, but maintaining high reflectance in the yellow region of the spectrum. Variation in this population is fairly minimal. The habitats in which these frogs were found 

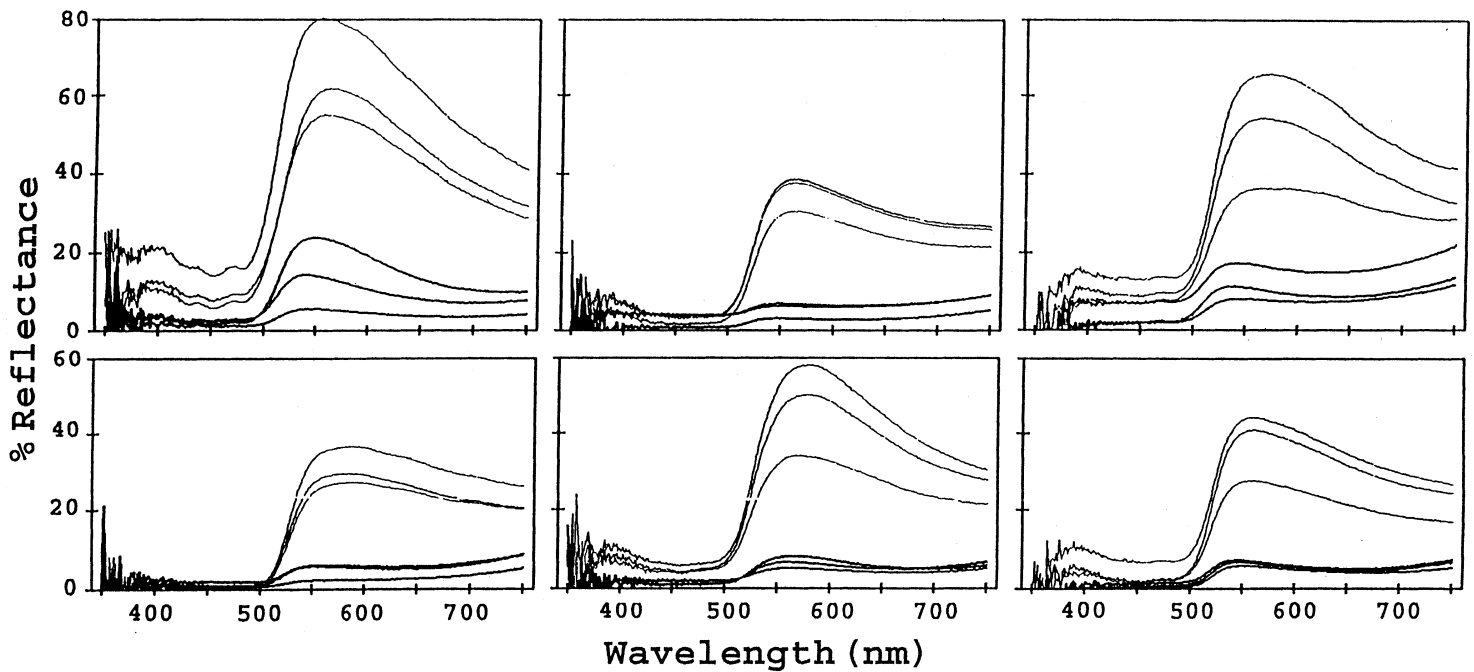

Figure 3 Spectral reflectances for six Dendrobates pumilio from Bocas Island. Three measurements are shown for the dorsal (thick lines) and ventral (thin lines) surface of the frog in each panel.
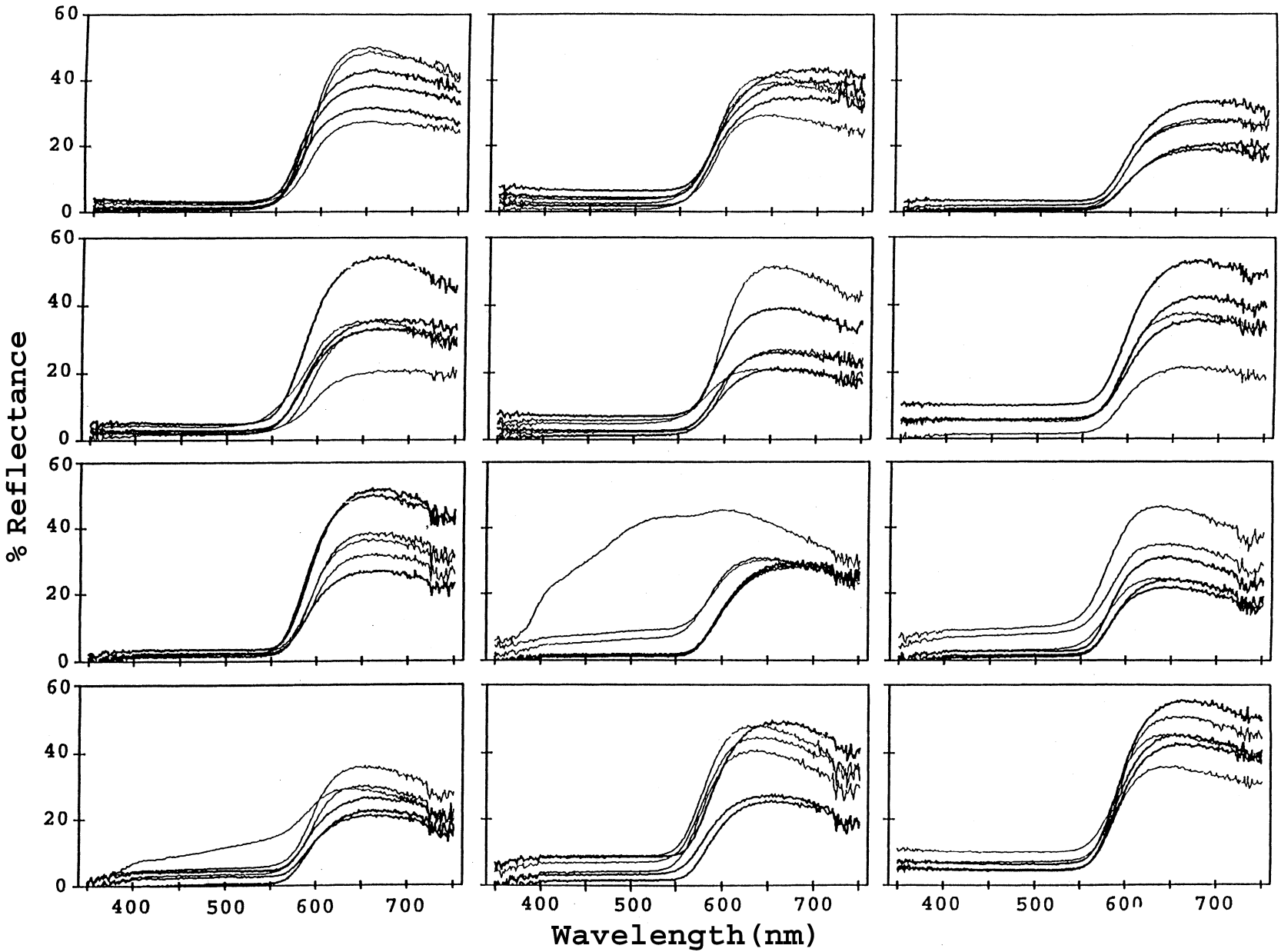

Figure 4 Spectral reflectances for twelve Dendrobates pumilio from Nancy Key. Three measurements are shown for the dorsal (thick lines) and ventral (thin lines) surface of the frog in each panel. 

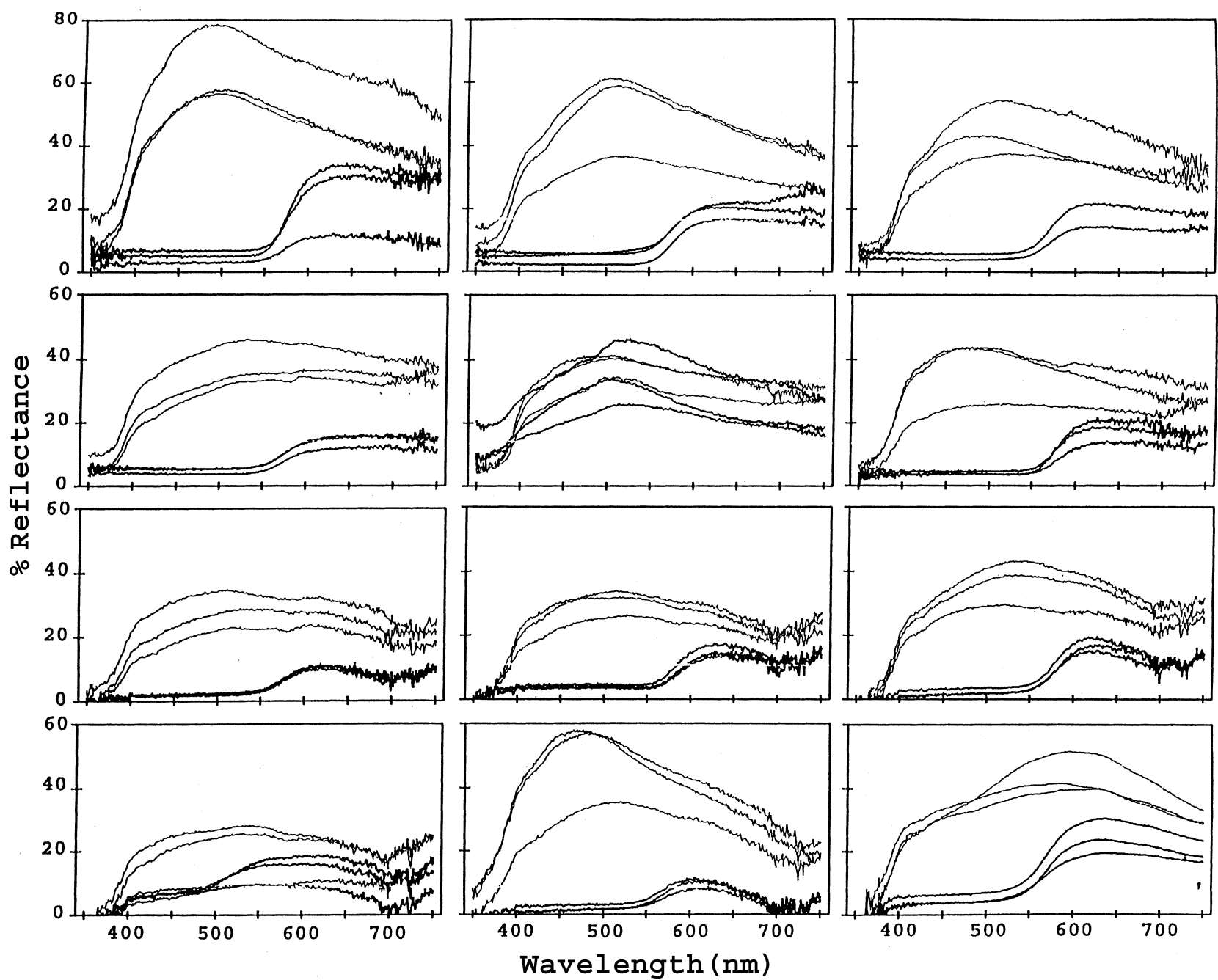

Figure 5 Spectral reflectances for twelve Dendrobates pumilio from Bastimentos Island. Three measurements are shown for the dorsal (thick lines) and ventral (thin lines) surface of the frog in each panel.

ranged from low marshy forest with substantial understory growth, to mature forest with a high canopy and a relatively open understory.

\section{Pope Island}

Frogs from Pope Island [Figs 1L and 2 (population 5)] also appear green, but there is variation in the colour of the venter, with frogs having yellowish venters in the southeastern part of the island, and frogs from the north-western side having bluish venters (not shown). The spectral reflectances measured (from frogs from the south-eastern part of the island) are similar to those of the Water Key and Bocas Island frogs (Fig. 7). Frogs on Pope Island have been found in very open secondary or even cultivated areas (in banana plantations), and in mature forest with a high canopy and open understory. They have also been found in marshy habitats next to the coast.

\section{Aguacate Peninsula}

The Aguacate Peninsula has frogs that appear to be entirely blue, with dark blue dorsal colour and bright powder blue venters [Figs 1 and 2 (population 6)]. The spectral reflectances for the dorsal surfaces of these frogs are fairly flat, with a small reflectance peak near $400 \mathrm{~nm}$ (Fig. 8). The ventral surfaces show a much more substantial peak of reflectance between 400 and $450 \mathrm{~nm}$, accounting for their bright blue appearance. These frogs have been found in primary forest, with a high canopy and open understory. They have also been found in cacao groves.

\section{San Cristobal Island}

Frogs from San Cristobal Island appear deep red on the dorsum and venter, with blue legs [Figs $1 \mathrm{~g}$ and 2 (population 7)]. Many frogs in this population have pronounced black speck- 

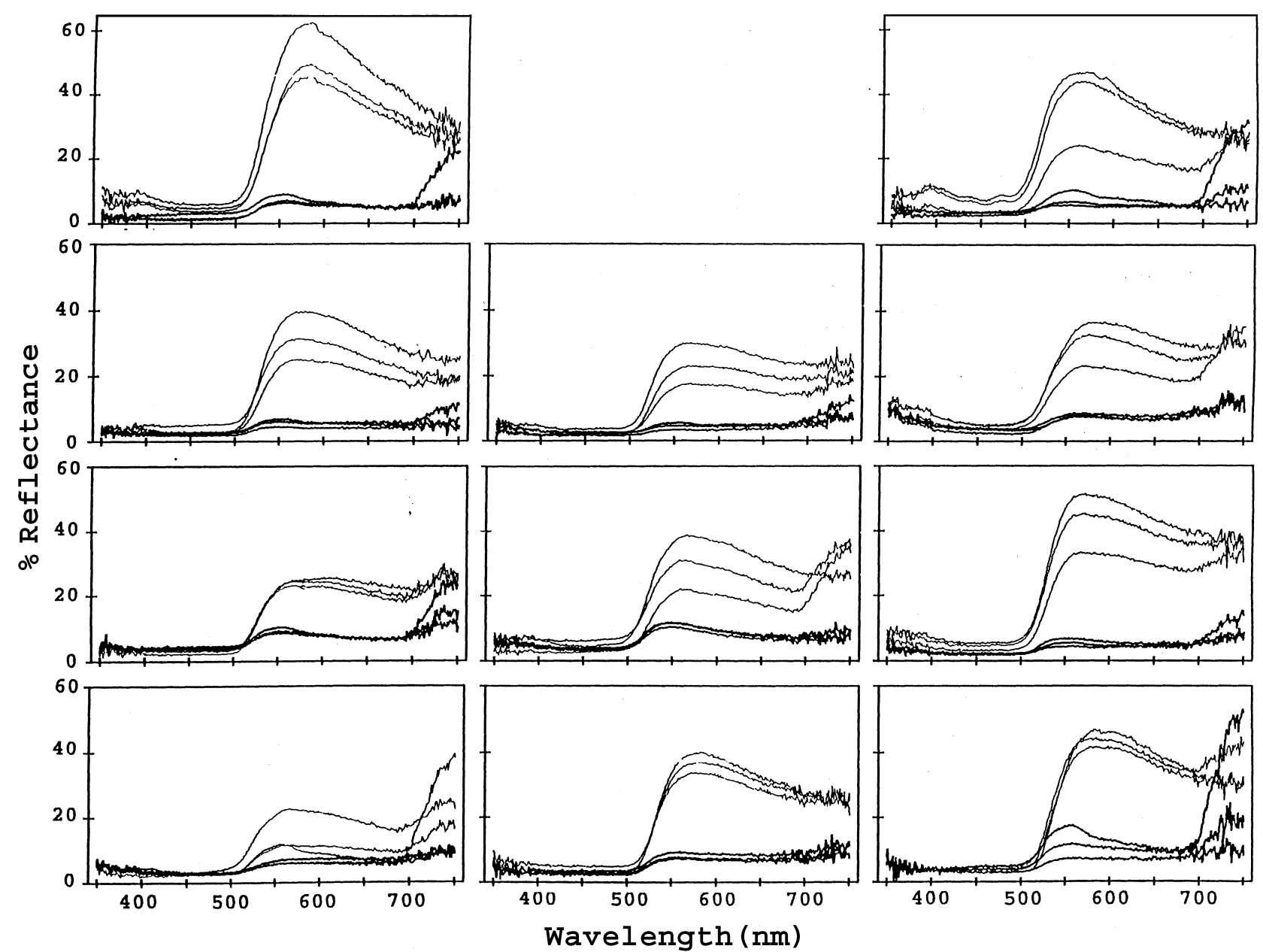

Figure 6 Spectral reflectances for eleven Dendrobates pumilio from Water Key. Three measurements are shown for the dorsal (thick lines) and ventral (thin lines) surface of the frog in each panel.

ling [Fig. 2(7)]. Frogs from this island appear similar to mainland frogs from the Almirante area (see below). We were only able to measure the spectral reflectance of one individual from this island (Fig. 9). This individual showed a peak of reflectance at about $625 \mathrm{~nm}$, with a shallow decline in reflectance thereafter. The habitat on San Cristobal Island has been highly modified due to human habitation and cultivation, and frogs on this island have been found only in cacao groves.

\section{Shepherd Island}

Frogs from Shepherd Island [Figs 1f and 2 (population 9)], appear to have uniformly beige green colour. Some frogs have faint speckling on their dorsum. Figure 10 shows the dorsal and ventral spectral reflectances for this population. Both dorsal and ventral surfaces show a peak around $550 \mathrm{~nm}$, accounting for their predominantly green colour. Unlike the frogs from Bocas Island, Water Key and Pope Island, both the dorsal and ventral spectral reflectances remain relatively flat, declining gradually. This probably accounts for the more yellow or beige appearance of these frogs. Also unlike the other green morphs of D. pumilio, the Shepherd Island frogs show a pronounced rise in reflectance in the infrared part of the spectrum. Shepherd Island is a small island, but has relatively dense forest. Frogs were found both in low marshy forest on the mainland side of the island, and on forested hillsides on the ocean side of the island. In both cases the understory vegetation was fairly dense. Figure $18 \mathrm{c}$ shows the spectral irradiance measured on the ocean side of the island.

\section{Pelican Key}

Frogs from Pelican Key [Fig. 2 (population 8)] appear very similar to those on Shepherd Island, with a beige-green colour on the dorsum and a yellowish-green on the venter. The spectral reflectances for both the dorsal and ventral surfaces peak at around $550 \mathrm{~nm}$, but tend to remain fairly flat, declining gradually (Fig. 11). These frogs also show a rise in reflectance in the infrared part of the spectrum. Pelican Key is a very small island just off the tip of Shepherd 


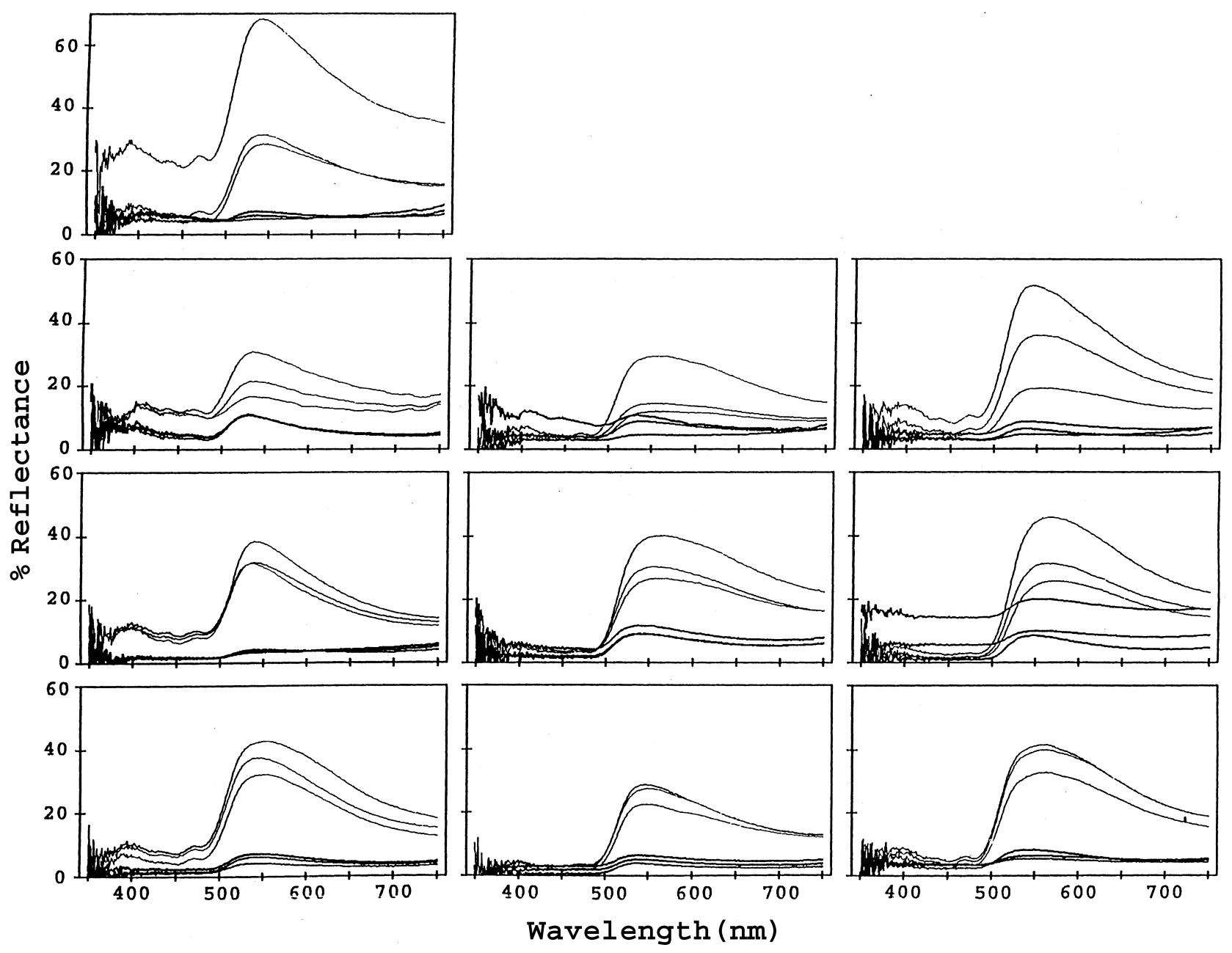

Figure 7 Spectral reflectances for ten Dendrobates pumilio from Pope Island. Three measurements are shown for the dorsal (thick lines) and ventral (thin lines) surface of the frog in each panel.

Island. There are several steep hills on the island, which are covered with low forest with relatively dense understory vegetation. Figure 18d shows the spectral irradiance measured on the ocean side of the island.

\section{Almirante}

Frogs from near Almirante on the mainland [Figs 1a and 2 (population 10)] have deep red dorsal and ventral surfaces, with slate blue legs. This is the classic D. pumilio morph that is widespread in eastern Costa Rica. The spectral reflectance of the dorsum peaks between 625 and $675 \mathrm{~nm}$, but remains relatively flat thereafter, with little or no decline (Fig. 12). This probably accounts for the deep red appearance of these frogs. The ventral surfaces show a higher peak around $650 \mathrm{~nm}$, with a sharper decline (Fig. 12). This leads to the brighter, more orange red of the venter of these frogs. These frogs are found from the coast right up into the mountains, in primary and secondary forest, as well as in cultivated areas (particularly areas cultivated with banana plants or cacao trees).

\section{Rio Uyama}

Frogs from the Rio Uyama area [Figs $1 \mathrm{~b}$ and 2 (population 11)] are black with highly variable calligraphic whitish markings. The whitish markings are tinged with a wide variety of different colours, ranging from blue to orange. The venter of these frogs have more extensive areas of tinged white colour, interspersed with smaller areas of black. The spectral reflectances of both the dorsal and ventral surfaces of these frogs are highly variable, but typically show substantial reflectance across the visual spectrum (Fig. 13). Peaks of reflectance occur at different places in different individuals, accounting for the multihued appearance of these frogs. These frogs are found in primary and secondary forest, as well as cacao groves and stands of banana plants. 


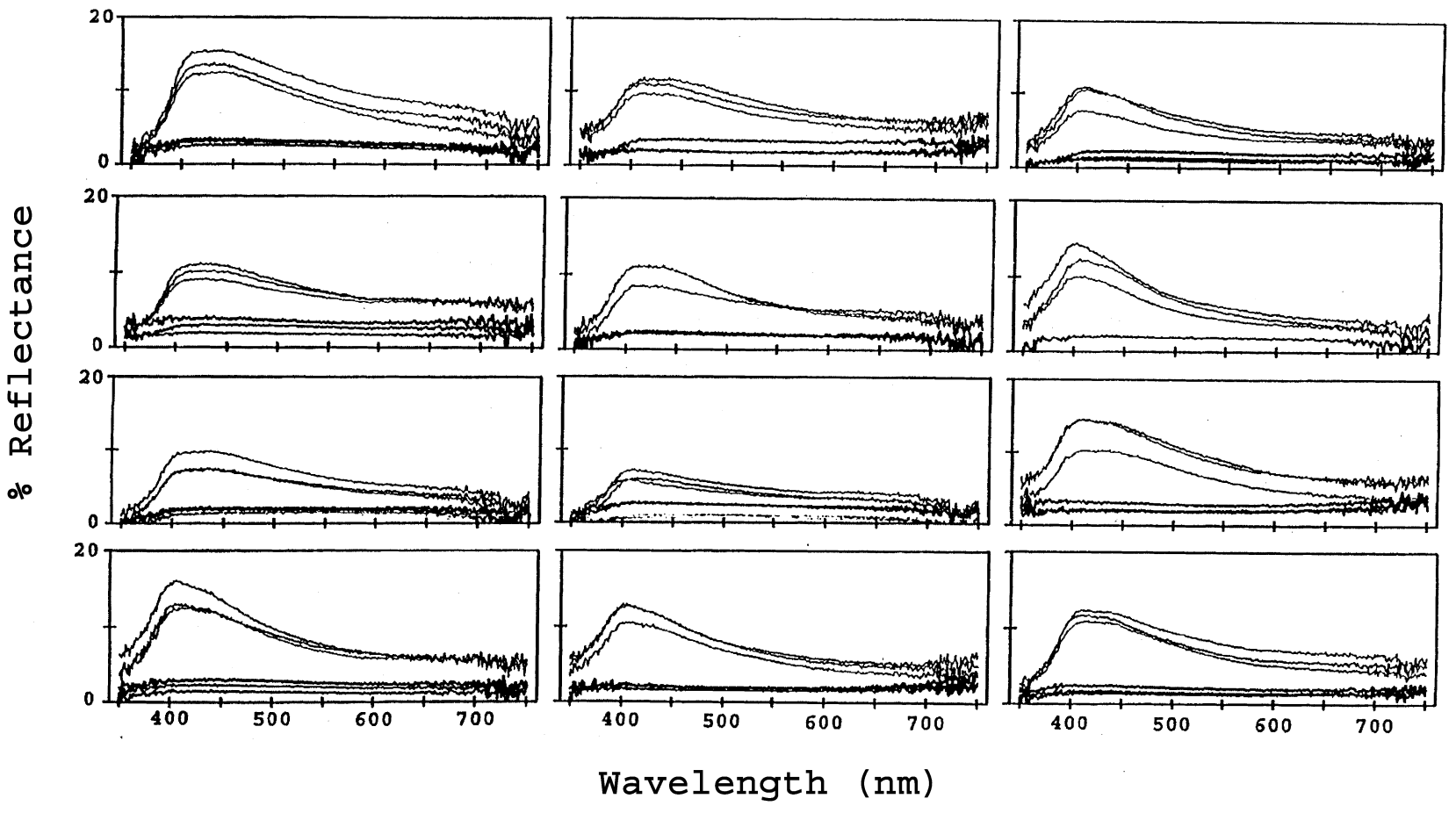

Figure 8 Spectral reflectances for twelve Dendrobates pumilio from the Aguacate Peninsula. Three measurements are shown for the dorsal (thick lines) and ventral (thin lines) surface of the frog in each panel.

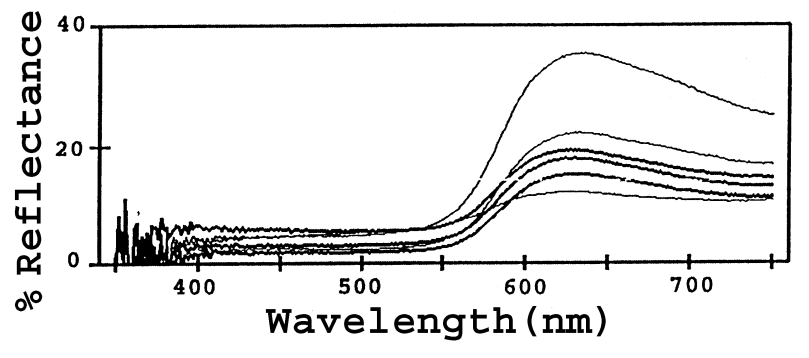

Figure 9 Spectral reflectances for one Dendrobates pumilio from San Cristobal Island. Three measurements are shown for the dorsal (thick lines) and ventral (thin lines) surface of the frog in each panel.

\section{Robalo River}

Frogs from near the Robalo River [Figs 1c and 2 (population 12)] are similar in some ways to the Rio Uyama frogs, but the striping is more extensive and appears distinctly yellow in colour, with whitish or yellowish markings on the legs. We were only able to measure the spectral reflectance for a single specimen from this area, which is shown in Fig. 14. The dorsal surface showed a peak at around $550 \mathrm{~nm}$, but remained relatively flat, declining gradually. This accounted for its yellow appearance. The ventral surface appeared whitish, but had a peak of reflectance around $460 \mathrm{~nm}$, giving it a blue-green tinge. These frogs have been found in primary forest with a high canopy and open understory, and in banana plantations.

\section{Guabo River}

Frogs from the forest between the Guabo River and the town of Chiriqui Grande [Figs 1d and 2 (population 13)] have forest green dorsal colour and light bluish-green venters. The spectral reflectances measured for this population are shown in Fig. 15. The dorsal surfaces show a peak between 525 and $550 \mathrm{~nm}$, accounting for their green appearance. Reflectance measured from the ventral region was considerably brighter and often showed substantial reflectance in the blue part of the spectrum, accounting for the bluish-green appearance of the venter in many individuals. Both the dorsal and ventral surfaces showed dramatic declines in reflectance at around $700 \mathrm{~nm}$, unlike the other populations with green colour. These frogs were found in disturbed swampy lowland forest. The canopy was high, with many mature trees, but the understory was fairly dense, and was dissected by numerous cattle trails.

\section{Chiriqui Grande}

Frogs from the hills above Chiriqui Grande [Figs 1e and 2 (population 14)] appear salmon-red dorsally with bluish-green ventral coloration. The spectral reflectance of the dorsal surfaces of these frogs show a gradual incline with a peak at around 625-650 nm (Fig. 16). The reflectance peak is substantially lower in these frogs relative to the Almirante population (Fig. 12), accounting for their 

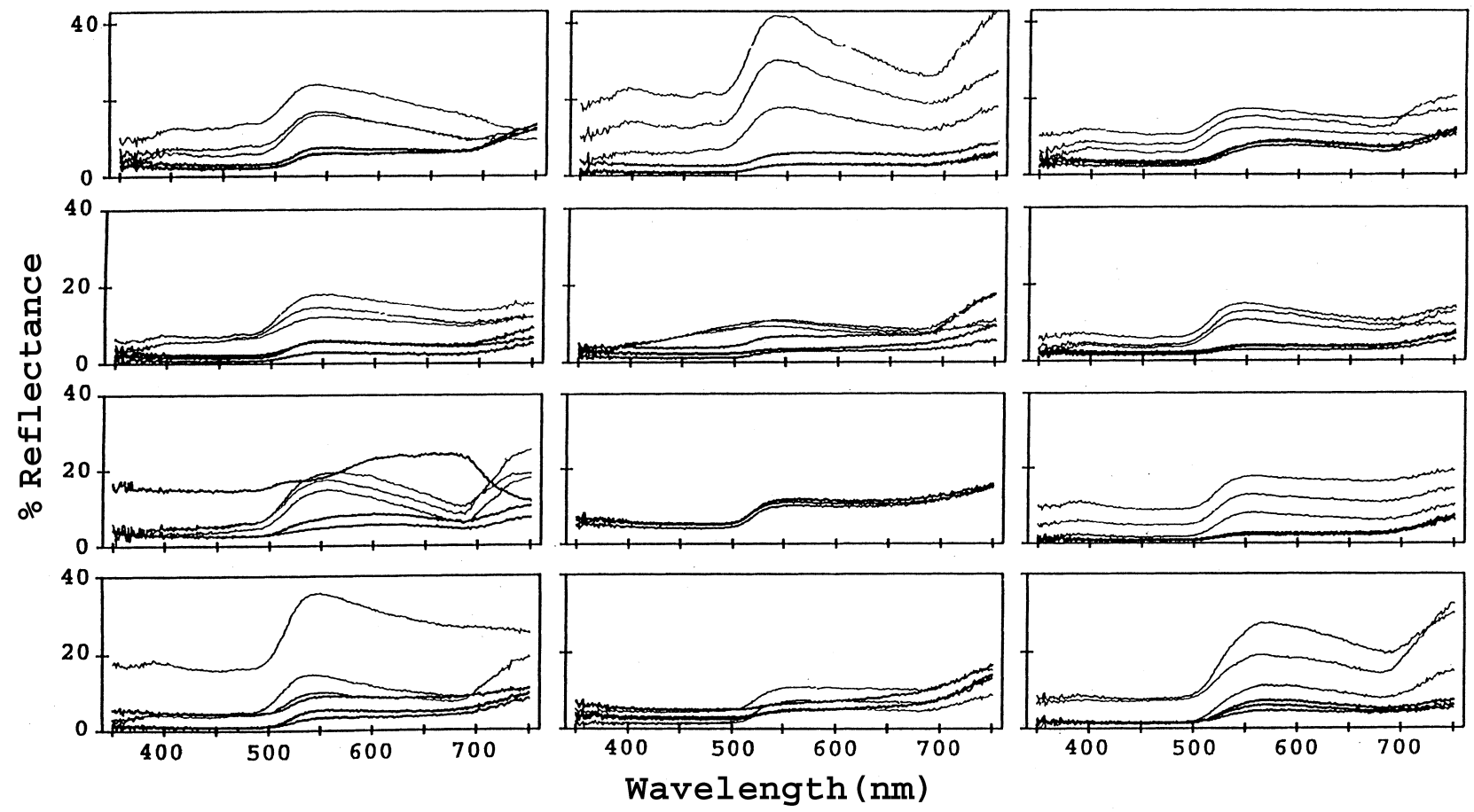

Figure 10 Spectral reflectances for twelve Dendrobates pumilio from Shepherd Island. Three measurements are shown for the dorsal (thick lines) and ventral (thin lines) surface of the frog in each panel.
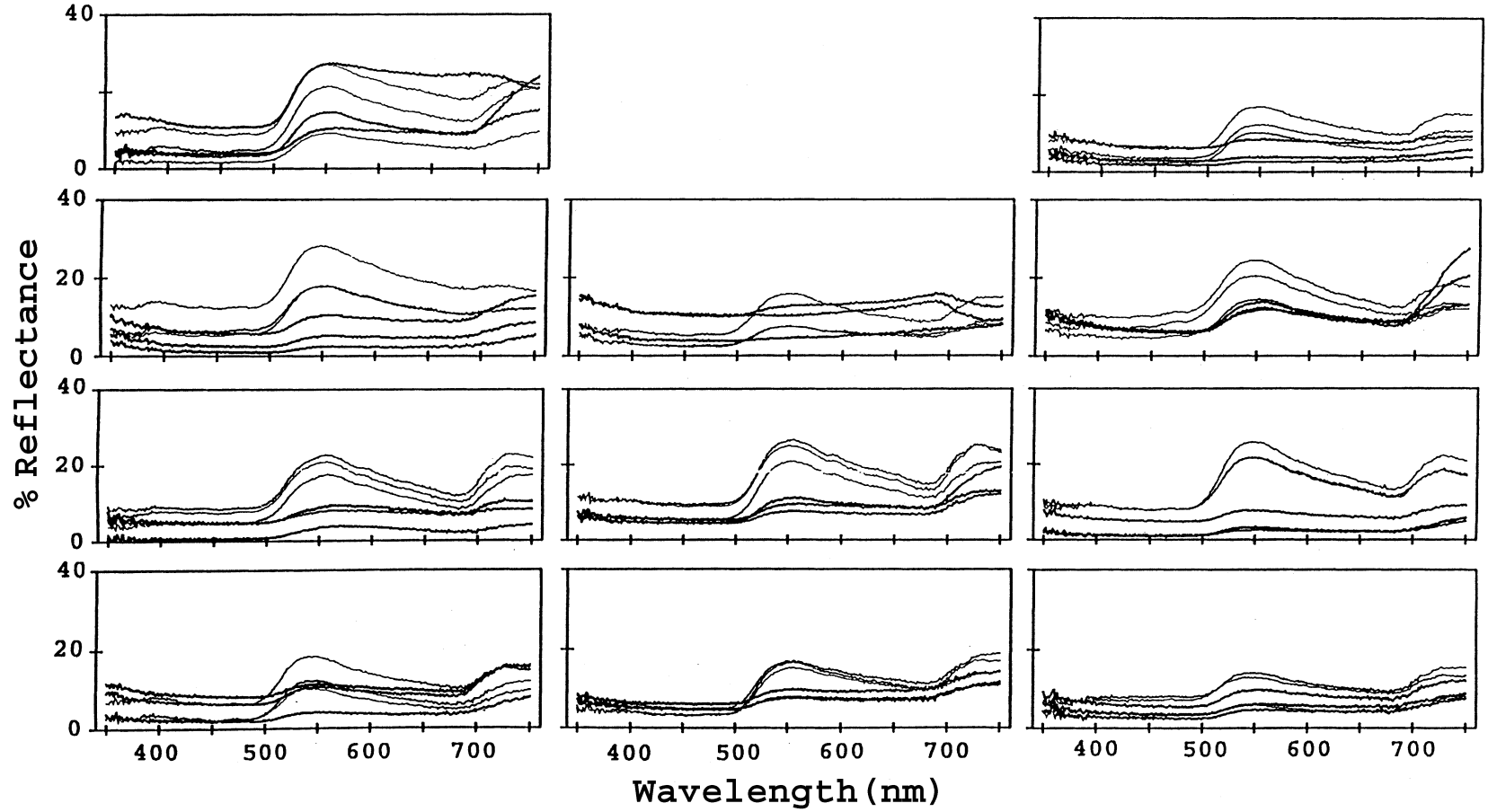

Figure II Spectral reflectances for eleven Dendrobates pumilio from Pelican Key. Three measurements are shown for the dorsal (thick lines) and ventral (thin lines) surface of the frog in each panel. 


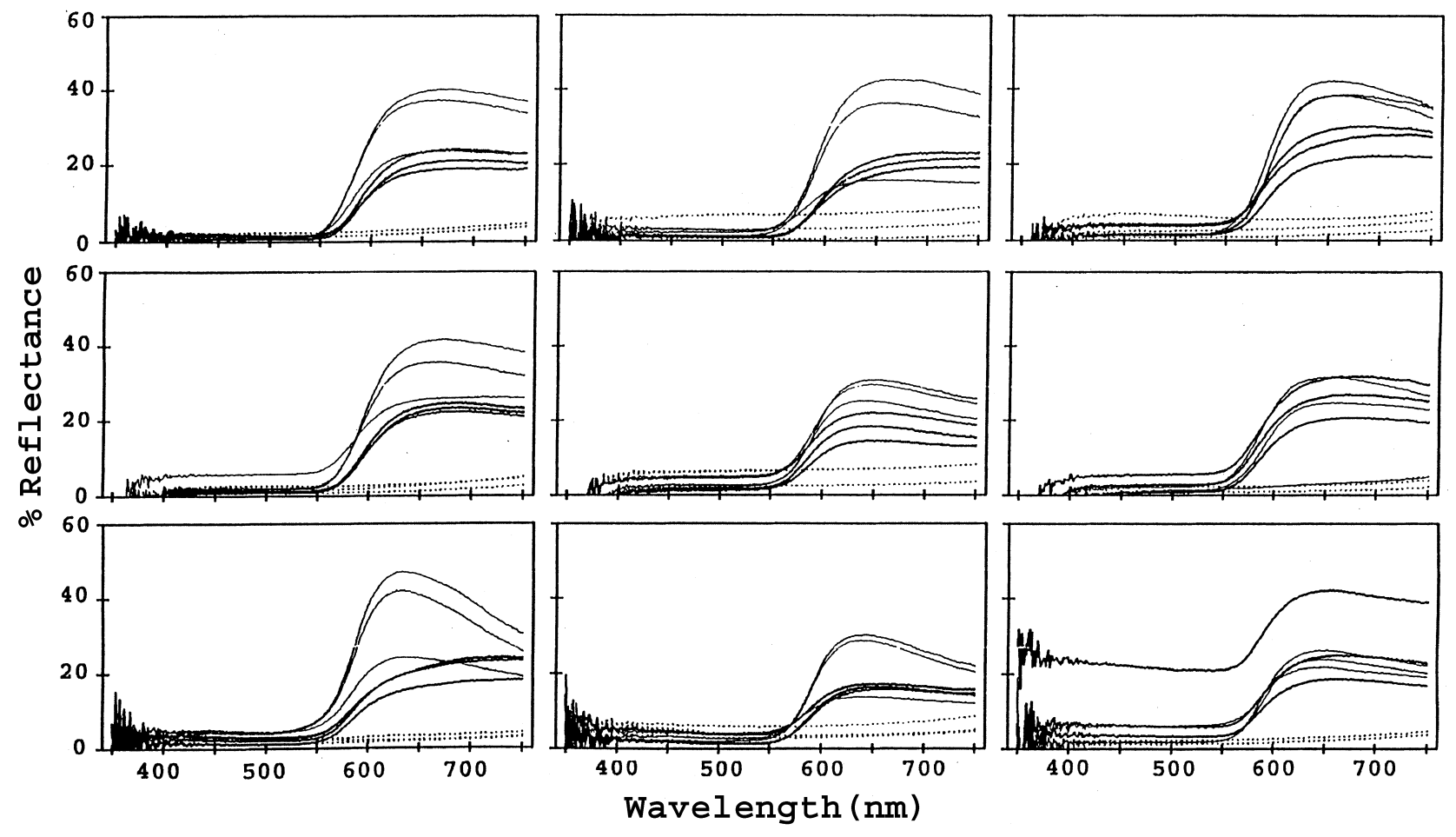

Figure 12 Spectral reflectances for nine Dendrobates pumilio from near Almirante. Three measurements are shown for the dorsal (thick lines) and ventral (thin lines) surface of the frog in each panel.
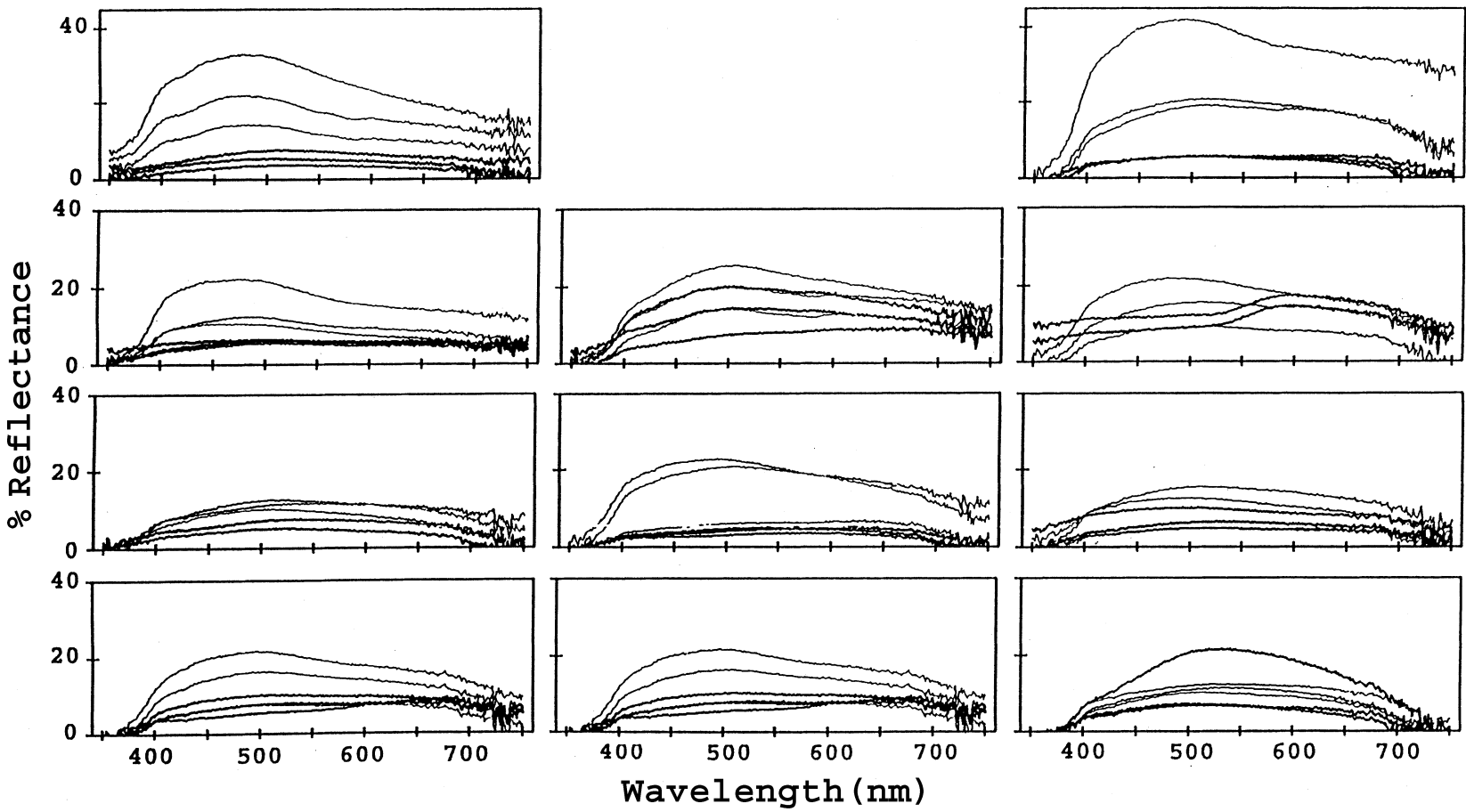

Figure 13 Spectral reflectances for eleven Dendrobates pumilio from near the Uyama River. Three measurements are shown for the dorsal (thick lines) and ventral (thin lines) surface of the frog in each panel. 


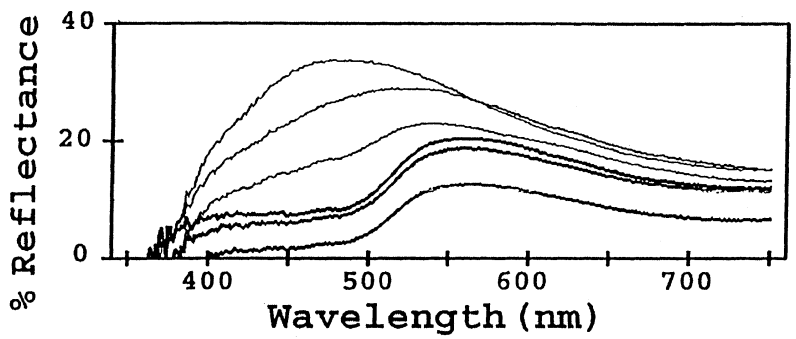

Figure 14 Spectral reflectances for one Dendrobates pumilio from near the Robalo River. Three measurements are shown for the dorsal (thick lines) and ventral (thin lines) surface of the frog in the panel.

duller appearance. The ventral surfaces tend to show substantial reflectance in the blue and green part of the spectrum, with a peak around $500 \mathrm{~nm}$ (Fig. 15). These frogs have been found in secondary forest and in cacao groves.

\section{Rambala}

Frogs resembling the morphs from Chiriqui Grande, the Guabo River and the Robalo River were all found in a single area near Rambala [Figs 1c, 1d, 1e and 2 (population 15)]. The spectral reflectances for these frogs are shown in Fig. 17. All these frogs were found on a single tree near the road, in secondary forest.

\section{Ambient Irradiance}

Measurements of downward irradiance taken at four sites (Nancy Key, Bastimentos Island, Shepherd Island and Pelican Key) are illustrated in Fig. 18. These data were collected at sites that appeared characteristic of the locality and were occupied by $D$. pumilio, and may be taken to represent typical light conditions under which the frogs are seen by conspecifics or predators. All measurements were of indirect light (in other words, not of direct sunlight), including either skylight or light filtered through the forest canopy. Measurements at Nancy Key and Bastimentos Island were acquired under a fairly open canopy, and the light is dominated by skylight (the measurements at Bastimentos Island were taken using a small-diameter fibre optic, which is why they show more fine detail). Here, spectra were fairly flat, particularly at wavelengths above $450 \mathrm{~nm}$. Those at Shepherd Island and Pelican Key were of light that had passed through vegetation, and thus show a clear peak in the green, near $550 \mathrm{~nm}$, due to absorption by chlorophyll. Despite the variations in lighting from site to site, at all locations the spectrum is relatively broad, supportive of colour vision throughout the spectrum from the ultraviolet to the red.

Based on their appearance to the human visual system, the fifteen populations can be categorized into ten different colour and pattern morphs (Table 1). Slight but visually apparent differences generally exist between populations in the same categories as well. For example, green and yellow morphs occur on Pope Island, Water

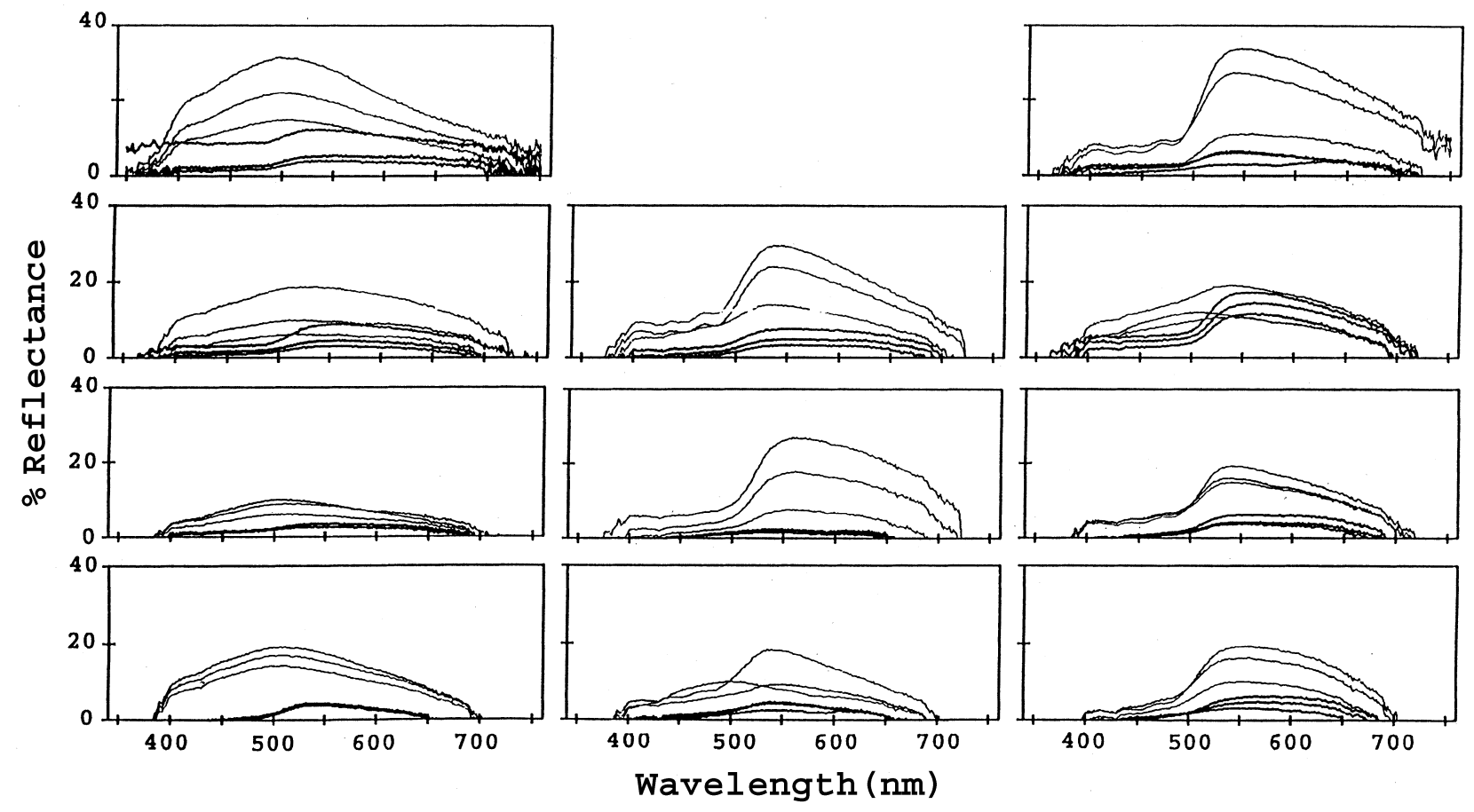

Figure 15 Spectral reflectances for eleven Dendrobates pumilio from near the Guabo River. Three measurements are shown for the dorsal (thick lines) and ventral (thin lines) surface of the frog in each panel. 

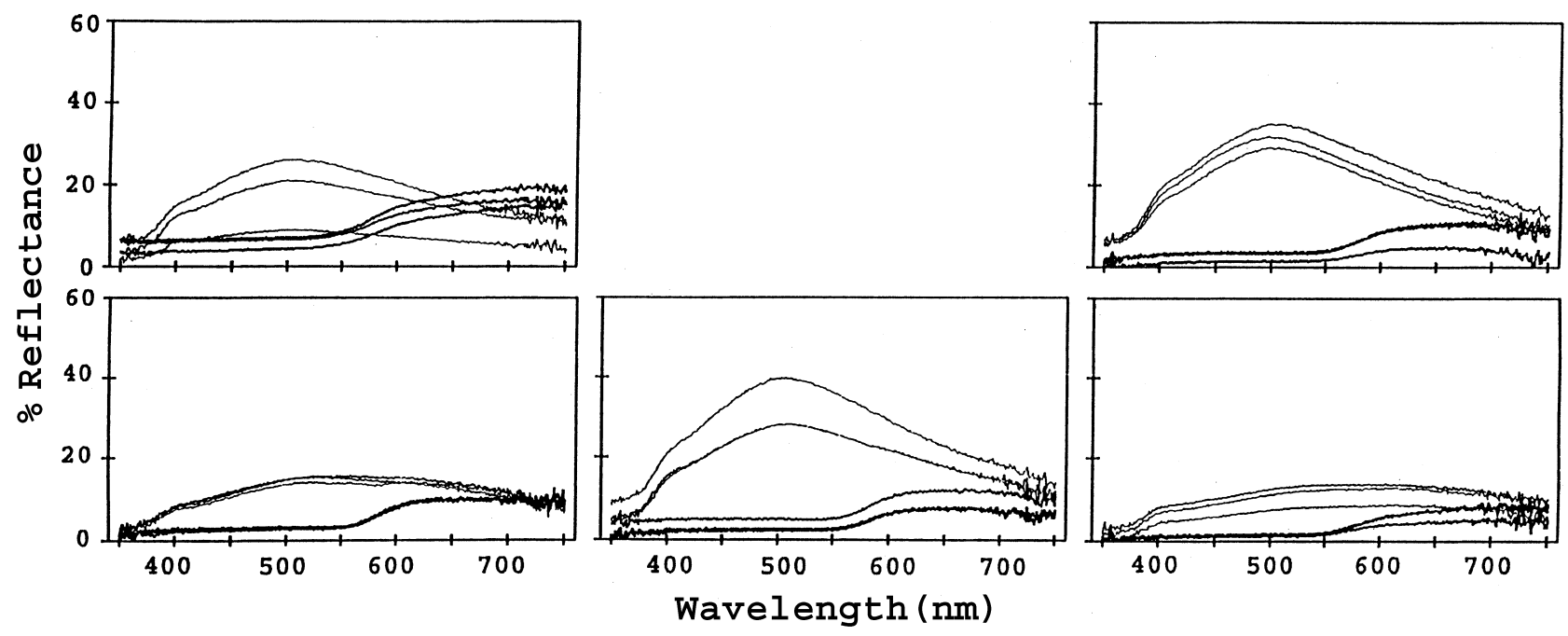

Figure 16 Spectral reflectances for five Dendrobates pumilio from Chiriqui Grande. Three measurements are shown for the dorsal (thick lines) and ventral (thin lines) surface of the frog in each panel.
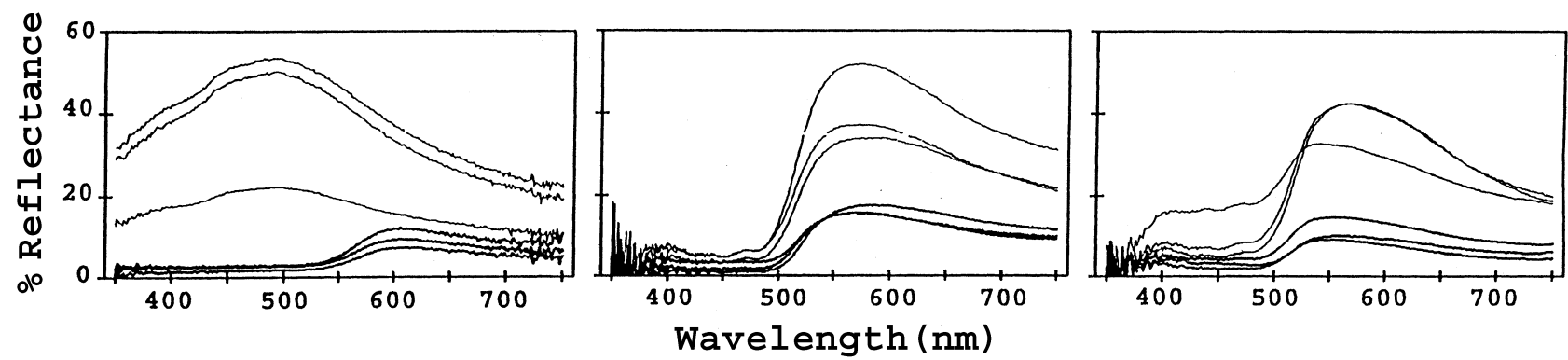

Figure 17 Spectral reflectances for three Dendrobates pumilio from near Rambala. The first panel on the left shows the spectral reflectance for a frog that appeared similar in colour to frogs measured at Chiriqui Grande (Fig. 16). The second panel shows the spectral reflectance measured for a frog that appeared similar to frogs from near the Robalo River (Fig. 14). The third panel shows the spectral reflectance from a frog that appeared similar to frogs found near the Guabo River (Fig. 15), but with a more yellowish hue and with dark blotches. Three measurements are shown for the dorsal (thick lines) and ventral (thin lines) surface of the frog in each panel.

Key and the Guabo River. However, the Water Key population has a more intense yellow colour on the venter than the other populations, and there is variation in the colour of the green morphs on Pope Island. The frogs from Shepherd Island and Pelican Key show a reflectance peak in the infrared part of the spectrum, whereas the frogs from Pope Island and Water Key show low reflectance in this region, and frogs from the Guabo region show virtually none.

As can be seen clearly by comparing Figs 1 and 2, populations with green colour are widely separated in many cases, suggesting that similar colour may have evolved repeatedly.

\section{DISCUSSION}

The analysis of colour presented here demonstrates the dramatic nature of the differences in spectral reflectance among these populations of $D$. pumilio. There are distinct differences in dorsal and ventral spectral reflectance among populations both on the islands and on the mainland. Conversely, some widely separated populations show similar spectral reflectances (particularly in the green region of the spectrum). Dispersal is unlikely to explain these observations, given the fact that green populations are interspersed with populations of different colours. The repeated occurrence of green colour could be due to convergent evolution of similar pigments. However, it may be more likely that the green pigments are the product of an ancestrally retained pigmentary synthesis pathway that has been modified to form other pigments in some populations. The production of green pigments could involve a relatively simple change in this pigmentary synthesis pathway, allowing frequent reversals during evolution.

Recently there has been considerable interest in the hypothesis that reflectance in the ultraviolet (UV) region of the spectrum may be more common than previously 


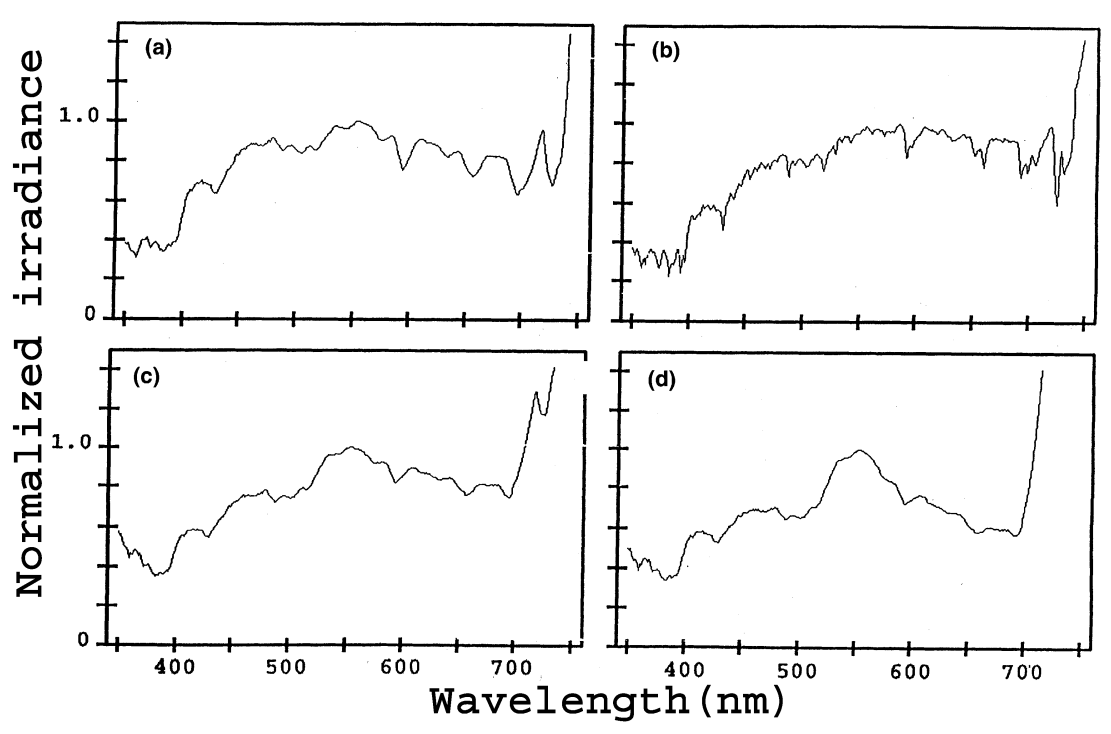

Figure 18 Normalized measurements of downward irradiance taken at four sites. (a) Nancy Key, (b) Bastimentos Island, (c) Shepherd Island, (d) Pelican Key. Curves were normalized to the following peak irradiances (all in photons $\mathrm{cm}^{-2} \mathrm{~nm}^{-1}$ ): (a) $4.63 \times 10^{11}$, (b) $9.52 \times 10^{12}$, (c) $1.15 \times 10^{12}$, (d) $4.86 \times 10^{11}$. appreciated, and that UV reflection may play a role in signalling, altering the appearance of an individual to other individuals with the capacity to see in the UV (e.g. Benett et al., 1996). There is little or no evidence that D. pumilio does have UV sensitive cones (E. Loew, pers. comm.), which would allow these frogs to perceive reflectance in that region of the electromagnetic spectrum. Moreover, our measurements suggest that all the different morphs of D. pumilio have very little reflectance in the UV, implying that UV colours may not be important for social interactions in this species.

Among the mainland populations there appears to be some evidence for clinal variation proceeding from the outskirts of Chiriqui Grande (near the Guabo River) north-west towards Almirante (Fig. 2, populations 13, 12 and 11). The clinal variation is particularly apparent with respect to dorsal colour and pattern, and proceeds as follows: Guabo River (green), Robalo River (black with yellow stripes), Uyama River (black with whitish stripes). Frogs that appeared intermediate between the green Guabo River frogs and the yellow-striped Robalo frogs have been found between these two populations (K. Summers, pers. observ.) although they were not sampled in this study. They show a yellowish-green dorsal colour, with dark stripes or blotches. The Robalo River and the Uyama River populations show similar striped patterns, but the Robalo River populations have consistently yellow stripes, whereas the stripes on the Uyama River frogs tend to be more whitish, with a wide variety of tints.

This clinal variation is punctuated at both ends by abruptly different colour morphs. Towards Almirante, there is an abrupt transition between the black and white morph and the red morph with blue legs. The transition occurs near the Quebrada Pittis, a small river. There is no obvious geographical barrier between the two morphs (the river is inconsequential compared with other large rivers in the area), but cursory searches of the area $($ c. $5 \mathrm{~km})$ between the two morphs have so far failed to reveal the presence of D. pumilio.

Two populations occur on opposite sides of the town of Chiriqui Grande, a green morph to the north-west (along the Guabo River) and a distinct morph to the south-east with a salmon-red dorsum and a bluish-green venter. Daly \& Myers (1967) suggested that differences in habitat may characterize the different morphs on either side of Chiriqui Grande (green and red) but this does not seem to be a general phenomenon. Three distinct morphs (salmon-red, yellowish-green with dark blotches and black with yellow stripes) have all been found at the same location (a single tree), near Rambala [Fig. 2 (population 15)]. While the yellowish-green and the yellow and black morphs may be part of a cline, the salmon red morph is distinctly different. The fact that it has been found in sympatry with the other two morphs suggests that incipient reproductive isolation may be occurring between some of the morphs.

Hybridization experiments between different morphs have been successful, indicating that these different morphs can probably interbreed successfully in the wild (K. Summers, T. Kennedy and T.W. Cronin, unpublished results). However, mate choice experiments using morphs from different island populations (a green morph from Pope Island and an orange morph from Nancy Key) demonstrated that each morph preferred to court with its own morphotype (Summers et al., 1999). Furthermore, captive breeding experiments suggest that different colour morphs are more likely to mate with members of their own morph than members of a different colour morph (R. Gagliardo, National Aquarium at Baltimore, p.c.). Hence it is possible that some degree of prezygotic isolation exists between these distinctly different morphs. Another possibility is that they have just come into contact recently.

The differences in colour and pattern between morphs in the Bocas del Toro Archipelago are likely to be caused by some form of selection, rather than genetic drift (Summers 
et al., 1997). The fact that there is substantial variation within some populations suggests the presence of underlying genetic variation, which is necessary for selection to be effective in producing change. However, the selective forces that have produced this dramatic diversification are still the subject of investigation (e.g. Summers et al., 1999).

Environmental differentiation among islands or habitats appears unlikely to explain the dramatic variation in colour and pattern among populations of $D$. pumilio. In lizards, variation in coloration is typically correlated with pronounced vegetation differences or differences in the abundance of rainfall associated with high levels of topographic relief (e.g. Malhotra \& Thorpe, 2000). The islands in the Bocas del Toro Archipelago are small, with locally diverse but regionally homogeneous vegetation (lowland rain forest) and little topographic relief. There is some habitat variation in the archipelago, but D. pumilio typically occupies primary and secondary lowland rain forest. Although there are differences between coastal and inland vegetation on the larger islands and on the mainland, these are not associated with differentiation in colour or pattern in $D$. pumilio. Most habitat heterogeneity in the habitats occupied by D. pumilio in the archipelago is associated with human-altered habitats (particularly cacao groves), which is a recent phenomenon and is not associated with colour morph divergence. Furthermore, habitat differences would be expected to cause similar divergence in other brightly coloured poison frogs inhabiting the same environments, but that is not the case (Summers et al., 1997).

Some of the colour morphs of D. pumilio (e.g. the green morphs) do not appear to be particularly brightly coloured to our visual system, and this is true for some other morphs as well, such as the blue morph from the Aguacate Peninsula. This has led to speculation that differences in colour might be associated with differences in toxicity among these populations (Daly \& Myers, 1967). Daly \& Myers (1967) tested this hypothesis by evaluating the toxicity of skin extracts from seven different populations to mice. They found no correlation between the apparent brightness of coloration and levels of toxicity. Hence, differences in toxicity do not appear to explain the divergence in coloration among D. pumilio populations. Selection for divergence in the context of Batesian mimicry (e.g. Savage \& Slowinski, 1996) is also unlikely to have driven divergence among populations of $D$. pumilio, because there are no known mimics of this species.

Sexual selection is another selective factor that may have driven divergence among populations of D. pumilio. As noted above, there are several different models of sexual selection and female choice, and these make somewhat different predictions regarding divergence. Indicator models of sexual selection seem unlikely to explain the variation observed in D. pumilio. These models assume that production of the indicator trait is inherently costly, and that variation in the cost of production (e.g. pigment scarcity) can lead to variation in the expression of the trait (Hill, 1994, 2000; Grether, 2000). Variation in the avail- ability of scarce pigments seems unlikely to explain variation in colour among populations of $D$. pumilio because such variation is typically associated with variation in the intensity or coloration, or slight variations in hue (e.g. Hill, 1994), not with the dramatic variations in hue found among the D. pumilio populations. Furthermore, because the genes involved in the production of the indicator trait (colour) are predicted to be sexually antagonistic (Rice \& Holland, 1997), they should show strong sexual dimorphism in expression. This does not appear to be the case in D. pumilio, because there is no apparent sexual dimorphism in colour or pattern.

In contrast, sensory drive and Fisherian runaway models of sexual selection do not require strong sexual antagonism (although they do not preclude it either). Under these models, sexual dimorphism may not exist, either because genetic correlations between the sexes cause females to resemble males, or because selection by predators favours convergence in appearance between the sexes (analogous to Müllerian mimicry between the sexes), reducing or eliminating sexual dimorphism even as sexual selection drives divergence between populations (Summers et al., 1997).

The sensory drive model predicts that different colours will be favoured by females in different populations because they are associated with some feature of the female's visual system that differs between islands or habitats but is not directly related to mating behaviour. For example, in sticklebacks, females in different lakes may prefer males of different colour because of differences in the availability of certain wavelengths of light (Boughman, 2001). This is possible for $D$. pumilio, but seems unlikely because differences in the light environments on different islands or habitats are relatively minor, and there are no other obvious differences in visual stimuli outside the context of mating (e.g. prey coloration).

In our opinion, Fisherian runaway sexual selection is a potentially viable explanation for the variation among populations of D. pumilio in the Bocas del Toro Archipelago (Summers et al., 1997). This kind of selection can cause rapid divergence between populations in species with female parental care (like D. pumilio), but would not be expected to cause divergence in species with male parental care. In the Bocas del Toro Archipelago, two other brightly coloured species of poison frogs occur, each of which has male parental care (Phyllobates lugubris and Minyobates species). These two species display little variation in coloration among populations in the archipelago (Summers et al., 1997).

Our results suggest that among population divergence accounts for the major proportion of variation in coloration and pattern in D. pumilio in the Bocas del Toro Archipelago. It is possible that phenotypic plasticity could contribute to some of the variation seen within populations of D. pumilio, but it cannot account for the dramatic differences among populations. The different colour morphs of this frog are true-breeding even when bred under identical conditions, and hybrids between morphs appear intermediate in colour, consistent with genetic control of coloration (R. Gagliardo, 
pers. comm.; K. Summers, T. Kennedy and T.W. Cronin, unpublished results).

There is no evidence that $D$. pumilio undergoes colour change in response to temperature. As part of a variety of investigations, one of us (K. Summers) has kept specimens of D. pumilio under both hot $\left(40^{\circ} \mathrm{C}\right)$ and cold $\left(4{ }^{\circ} \mathrm{C}\right)$ conditions. This treatment did not produce any noticeable change in coloration. As in many lowland tropical localities, the temperature in Bocas del Toro shows only minor fluctuations, relative to temperate climates. Hence, it is perhaps not surprising that $D$. pumilio does not appear to utilize colour change for thermoregulatory purposes. Changes in coloration have been observed in captive red specimens of $D$. pumilio from Bastimentos Island, involving gradual fading of the red colour over many years (approximately 10) until the red coloration is quite faint (R. Gagliardo, National Aquarium at Baltimore, pers. comm.). The proximate basis of these changes is not known. Such extreme fading has not been observed in the wild, although differences in the intensity of red among individuals within populations could conceivably be associated with age-related fading.

\section{ACKNOWLEDGMENTS}

We thank the staff of the Smithsonian Tropical Research Institute for support with all parts of the project, especially Luis Moe, Lulu and Bibi Ferenbach. Special thanks to Maria Leone for assistance with permits. We thank the Ministry of the Environment in Panama (ANAM) for granting research, collection and exportation permits for this research. This work is based on research supported by the National Geographic Society under grant number $6702-00$, and by the National Science Foundation under grant number IBN-9724028. We thank Stan Rand and Roberto Ibanez for advice on the project.

\section{REFERENCES}

Aldrich, J.W. \& James, F.C. (1991) Ecogeographic variation in the American robin (Turdus migratorius). Auk, 108, 230249.

Anderson, R.S. \& Peck, S.B. (1986) Geographic patterns of colour variation in North American Nicrophorus burying beetles (Coleoptera; Silphidae). Journal of Natural History, 20, 283-297.

Bagnara, J.T. (1966) Cytology and cytophysiology of nonmelanophore pigment cells. International Review of Cytology, 20, 173-205.

Bagnara, J.T. \& Fernandez, P.J. (1993) Hormonal influences on the development of amphibian pigmentation patterns. Zoological Science, 10, 733-748.

Benett, A., Cuthill, I., Partridge, J. \& Maier, E. (1996) Ultraviolet vision and mate choice in zebra finches. Nature, 380, 433-435.

Boughman, J.W. (2001) Divergent sexual selection enhances reproductive isolation in sticklebacks. Nature, 411, 944-948.

Browder, L.W. (1968) Pigmentation in Rana pipiens. 1. Inheritance of the speckle mutation. Journal of Heredity, 59, 162-166.
Brown, R.P. \& Thorpe, R.S. (1991) Within-island microgeographic variation in the colour pattern of the skink, Chalcides sexlineatus: Pattern and cause. Journal of Evolutionary Biology, 4, 557-574.

Cott, H.B. (1940) Adaptive Coloration in Animals. Meuthen and Co. Ltd Press, London.

Daly, J.W. \& Myers, C.W. (1967) Toxicity of Panamanian poison frogs (Dendrobates): some biological and chemical aspects. Science, 156, 970-973.

Dearn, J.M. (1984) Colour pattern polymorphism in the grasshopper Phaulacridium vittatum. I. Geographic variation in Victoria and evidence of habitat association. Australian Journal of Zoology, 32, 239-249.

Duellman, W.E. (1973) Frogs of the Hyla geographica group. Copeia, 3, 515-533.

Frost-Mason, S., Morrison, R. \& Mason, K (1994) Pigmentation. Amphibian Biology (ed. H. Heatwole). Surrey Beatty \& Sons, Chippiing, Norton, New South Wales.

Grether, G.F. (2000) Carotenoid limitation and mate preference evolution: a test of the indicator hypothesis in guppies (Poecilia reticulata). Evolution, 54, 1712-1724.

Gubitz, T., Thorpe, R.S. \& Malhotra, A. (2000) Phylogeography and natural selection in the Tenerife gecko Tarentola delalandii: testing historical and adaptive hypotheses. Molecular Ecology, 9, 1213-1221.

Haugen, L. (1992) Background color selection and color change in the cryptic hylid frog, Psuedacris Regilla. Unpublished Master Thesis, California State University, Northridge.

Hayes, T.B. \& Menendez, K.P. (1999) The effect of sex steroids on primary and secondary sex differentiation in the sexually dichromatic reedfrog (Hyperolius argus: Hyperolidae) from the Arabuko Sokoke forest of Kenya. General and Comparative Endocrinology, 115, 188-199.

Heyer, W.R. (1997) Geographic variation in the frog genus Vanzolinius (Anura: Leptodactylidae). Proceeding of the Biology Society of Washington, 110, 338-365.

Hill, G.E. (1994) Geographic variation in male ornamentation and female mate preference in the house finch: a comparative test of models of sexual selection. Behavioral Ecology, 5, 64-73.

Hill, G.E. (2000) Energetic constraints on expression of carotenoid-based plumage coloration. Journal of Avian Biology, 31, 559-566.

Hoffman, E.A. \& Blouin, M.S. (2000) A review of colour and pattern polymorphism in anurans. Biology Journal of the Linnaen Society, 70, 633-665.

Iwasa, Y. \& Pomiankowski, A. (1995) Continual change in mate preferences. Nature, 377, 420-422.

Joron, M. \& Mallet, J. (1999) Diversity in mimicry: paradox or paradigm? Trends in Ecology and Evolution, 13, 461-466.

Kemp, D.J. \& Jones, R.E. (2000) Phenotypic plasticity in field populations of the tropical butterfly Hypolimnas bolina (L.) (Nymphalidae). Biology Journal of the Linnean Society, 72, 33-45.

Mackey, J.P. (1958) Morphological variation among populations of the pacific tree frog (Hyla regilla Baird and Girard) at several elevations in western Oregon. Unpublished DPhil Thesis, University of Oregon. Eugene, OR.

Malhotra, A. \& Thorpe, R.S. (2000) The dynamics of natural selection and vicariance in the Dominican anole: Patterns of 
within-island molecular and morphological divergence. Evolution, 54, 245-258.

Mallet, J. \& Joron, M. (1999) The evolution of diversity in warning colour and mimicry: polymorphisms, shifting balance, and speciation. Annual Review of Ecology and Systematics, 30, 201-233.

Matthews, W.J. (1995) Geographic variation in nuptial colors of red shiner (Cyprinella lutrensis, Cyprinidae) within the United States. Southwestern Naturalist, 40, 5-10.

McCoy, J.K., Harmon, H.J., Baird, T.A. \& Fox, S.F. (1997) Geographic variation in sexual dichromatism in the collared lizard, Crotaphytus collaris (Sauria: Crotaphytidae). Copeia, 1997, 565-571.

Myers, C.W. \& Daly, J.W. (1976) Preliminary evaluation of skin toxins and vocalization in taxonomic and evolutionary studies of poison-dart frogs (Dendrobatidae). Bulletin of the American Museum of Natural History, 157, 173-262.

Myers, C.W. \& Daly, J.W. (1983) Poison dart frogs. Scientific American, 248, 120-133.

Nussbaum, R.A. \& Wu, S.H. (1995) Distribution, variation, and Systematics of the Seychelles Treefrog, Tachynemis seychellensis (Amphibia, Anura, Hyperoliidae). Journal of Zoology, 236, 383-406.

Passmore, N.I. \& Carruthers, V.C. (1979) South African Frogs. Witwatersrand University Press, Johannesburg.

Rice, W.R. \& Holland, B. (1997) The enemies within: intergenomic conflict, interlocus content evolution (ICE), and the intraspecific Red Queen. Behavioural Ecology and Sociobiology, 41(1), 1-10.

Richards, C.M. (1982) The alteration of chromatophore expression by sex hormones in the Kenyan reed frog, Hyperolius viridiflavus. General and Comparative Endocrinology, 46, 59-67.

Savage, J.M. \& Slowinski, J.B. (1996) Evolution of coloration, urotomy and coral snake mimicry in the snake genus Scaphiodontophis (Serpentes: Colubridae). Biology Journal of the Linnaen Society, 57, 129-194.

Seehausen, O., van Alpen, J.J.M. \& Witte, F. (1997) Cichlid fish diversity threatened by eutrophication that curbs sexual selection. Science, 277, 1808-1811.

Speed, M. \& Turner, J. (1999) Learning and memory in mimicry. II. Do we understand the mimicry spectrum? Biology Journal of the Linnean Society, 67, 281-312.

Summers, K., Bermingham, E., Weigt, L., McCafferty, S. \& Dahlstrom, L. (1997) Phenotypic and mitochondrial DNA divergence in three species of dart-poison frogs with contrasting parental care behavior. Journal of Heredity, 88, 8-13.

Summers, K. \& Clough, M. (2001) The evolution of coloration and toxicity in the poison frogs. Proceedings of the National Academy of Sciences, USA, 98, 6227-6232.

Summers, K., Symula, R., Clough, M. \& Cronin, T.W. (1999) Visual mate choice in poison frogs. Proceedings of the Royal Society, Series B, 266, 1-5.

Sutton, D.A. \& Patterson, B.D. (2000) Geographic variation of the western chipmunks Tamias senex and T-siskiyou, with two new subspecies from California. Journal of Mammologyalogy, 81, 299-316.

Wiens, J.J., Reeder, T.W. \& De Oca, A.N.M. (1999) Molecular phylogenetics and evolution of sexual dichromatism among populations of the Yarrow's spiny lizard (Sceloporus jarrovii). Evolution, 53, 1884-1897.

Woodruf, D.S. (1975) Morphological and geographic variation of Pseudophryne corroboree (Anura: Leptodactylidae). Records of the Australian Museum, Sydney, 30, 99-113.

Zink, R.M. \& Remsen, J.V. Jr (1986) Evolutionary processes and patterns of geographic variation in birds. Current Ornithology, 4, 1-69.

\section{BIOSKETCHES}

Kyle Summers is an Associate Professor of Biology at East Carolina University in North Carolina. He received his $\mathrm{PhD}$ from the University of Michigan in 1990. His research interests include evolutionary ecology and molecular systematics and phylogeography, particularly of the poison frogs of South and Central America.

Thomas W. Cronin is a Professor of Biological Sciences, University of Maryland Baltimore County. He received his $\mathrm{PhD}$ from Duke University in 1979. His research interests include the ecology and evolution of vision. He works primarily on the visual systems of marine animals, but is also interested in general problems of eye design, colour vision and its optimization for particular environments and tasks, polarization vision, and visual signalling and communication. 